NBER WORKING PAPER SERIES

\title{
THE CAUSES AND CONSEQUENCES OF ATTENDING HISTORICALLY BLACK COLLEGES AND UNIVERSITIES
}

\author{
Roland G. Fryer \\ Michael Greenstone \\ Working Paper 13036 \\ http://www.nber.org/papers/w13036
NATIONAL BUREAU OF ECONOMIC RESEARCH
1050 Massachusetts Avenue
Cambridge, MA 02138
April 2007

We are grateful to David Card, David Cutler, Bryan Graham, Chang-Tai Hsieh, Lawrence Katz, Henry Louis Gates, Jr., Edward Glaeser, Lani Gunier, Caroline Hoxby, Glenn Loury, Enrico Moretti, Andrei Shleifer, Lawrence Summers, colleagues at the Mellon Foundation, and participants in numerous seminars. Fryer is especially thankful to the Michor family in Kritzendorf, Austria for their support and generous hospitality while working on the paper. This paper makes use of the College and Beyond (C\&B) database. The $\mathrm{C} \& \mathrm{~B}$ database is a restricted-use database. Researchers who are interested in using the database may apply to the Andrew W. Mellon foundation for access. Sam Schulhofer-Wohl, Sheldon Bond, Jörg Spenkuch, Elizabeth Greenwood, and Paul Torelli provided exceptional research assistance. All errors are our own. The views expressed herein are those of the author(s) and do not necessarily reflect the views of the National Bureau of Economic Research.

(C) 2007 by Roland G. Fryer and Michael Greenstone. All rights reserved. Short sections of text, not to exceed two paragraphs, may be quoted without explicit permission provided that full credit, including (C) notice, is given to the source. 
The Causes and Consequences of Attending Historically Black Colleges and Universities

Roland G. Fryer and Michael Greenstone

NBER Working Paper No. 13036

April 2007

JEL No. I23,J15

\begin{abstract}
$\underline{\text { ABSTRACT }}$
Until the 1960s, Historically Black Colleges and Universities (HBCUs) were practically the only institutions of higher learning open to Blacks in the US. Using nationally representative data files from 1970s and 1990s college attendees, we find that in the 1970s HBCU matriculation was associated with higher wages and an increased probability of graduation, relative to attending a Traditionally White Institution (TWI). By the 1990s, however, there is a wage penalty, resulting in a $20 \%$ decline in the relative wages of HBCU graduates between the two decades. We also analyze the College and Beyond's 1976 and 1989 samples of matriculates which allows us to focus on two of the most elite HBCUs. Between the 1970s and 1990s, HBCU students report statistically significant declines in the proportion that would choose the same college again, preparation for getting along with other racial groups, and development of leadership skills, relative to black students in TWIs. On the positive side, HBCU attendees became relatively more likely to be engaged in social, political, and philanthropic activities. The data provide modest support for the possibility that HBCUs' relative decline in wages is partially due to improvements in TWIs' effectiveness at educating blacks. The data contradict a number of other intuitive explanations, including relative decline in pre-college credentials (e.g., SAT scores) of students attending HBCUs and expenditures per student at HBCUs.
\end{abstract}

\author{
Roland G. Fryer \\ Department of Economics \\ Harvard University \\ Littauer Center, M-7 \\ Cambridge, MA 02138 \\ and NBER \\ rfryer@fas.harvard.edu \\ Michael Greenstone \\ Department of Economics \\ Massachusetts Institute of Technology \\ 50 Memorial Drive E52-359 \\ Cambridge, MA 02142-1347 \\ and NBER \\ mgreenst@mit.edu
}




\section{Introduction}

Historically Black Colleges and Universities (HBCUs) have a proud and storied role in the education and progress of Blacks in America. For nearly a century, Historically Black Colleges and Universities (HBCUs) were practically the only institutions of higher learning open to Blacks in the US. Today, roughly $20 \%$ of all college going Blacks chooses to attend one of the 103 HBCUs and these institutions are responsible for $22 \%$ of current bachelor's degrees granted to Blacks. W.E.B. Dubois (Wilberforce), Ralph Ellison (Tuskegee), Martin Luther King, Jr. (Morehouse), Thurgood Marshall (Lincoln), Ruth Simmons (Dillard), and Oprah Winfrey (Tennessee State) headline a long list of famous HBCU alumni. Among Blacks, $40 \%$ of all congressmen, $12.5 \%$ of CEOs, $50 \%$ of professors at nonHBCUs, $50 \%$ of lawyers, and $80 \%$ of judges are HBCU graduates. ${ }^{1}$

HBCUs' successes are in no small part due to their substantial financial support from federal, state, and to a lesser degree, local governments. Between 1977 and 2001, 61\% to 73\% of public HBCUs revenues came from public funds. While numbers are smaller for private HBCUs, public support still accounts for nearly a third of total revenues. In the years 1999-2001, annual total public support of HBCUs averaged roughly \$2.65 billion (2005\$) (Provasnik et al. 2004).

Despite their past successes and historical importance, HBCUs are at a crossroads today. In U.S. v. Fordice (505 U.S. 717 (1992)), the Supreme Court instructed state legislatures to find "educational justification" for the existence of HBCUs or integrate them; the latter would completely alter their mission. In response, some HBCUs experienced declines in enrollment, others have pursued dramatic increases in the fraction of non-Black students, and a number of HBCUs have seen important declines in their financial positions. ${ }^{2}$

The Supreme Court's call for an "educational justification" is surely related to the absence of convincing evidence on the causes and consequences of attending an HBCU for Blacks. HBCU proponents claim that they provide an idyllic learning environment that is free from the pressures of discrimination and racism. It is also argued that HBCUs help to build important social capital for Blacks by engendering a strong sense of communal responsibility and civic consciousness and providing networking opportunities for high achieving Blacks (Drewry and Doermann 2001). If these arguments are correct, then HBCUs offer unique opportunities for educational and social development of Black students and the argument for remaining segregated seems justified.

\footnotetext{
${ }^{1}$ The data sources are Congressional Black Caucus (congressmen), Black Enterprise (CEOs), US Department of Education, Office of Civil Rights (professors), and Ehrenberg (1996) (Lawyers and Judges).

${ }^{2}$ The ruling had an adverse effect on many HBCUs. Alcorn State experienced a 9.9\% decrease in enrollment and Mississippi Valley State a 20.1\% decrease. Other HBCUs, especially in North Carolina, have shown substantial increases in integration. Elizabeth City State increased from 11\% white in 1980 to 23. 7\% in 1998, Fayetteville State from 11.9 to 22.2, North Carolina Central from 4.1 to 13.4, and Winston Salem from 11.3 to 18.0. In other states, such as Florida, the ruling has been largely ignored; Florida A\&M remains $90 \%$ black.
} 
On the other hand, it is possible that HBCUs are inferior to Traditionally White Institutions (TWIs) in preparing Blacks for post-college life. If students are taking less challenging courses from less distinguished faculty, have access to poor resources, or are not investing in the social skills necessary to interact with diverse sets of people, then graduates will perform poorly in the labor market and have inferior non-labor market outcomes. In this scenario, the case for supporting HBCUs with public resources appears weak.

This paper empirically assesses the causes and consequences of HBCU attendance so that the future decisions by governments, students, and parents are based on evidence, rather than theories and historical anecdotes. We analyze three large data sets with adequate pre and post college information for Blacks that identify the students' choice of college and whether it is an HBCU. The data sets are: the National Longitudinal Survey of the High School Class of 1972 (NLS-72), Baccalaureate and Beyond $(\mathrm{B} \& \mathrm{~B})$, and the College and Beyond database $(\mathrm{C} \& \mathrm{~B})$. The first two datasets provide a snapshot of a nationally representative sample of HBCU students at two points in time: 1972 and 1992. The third dataset contains four HBCUs, Howard, Morehouse, Spelman, and Xavier, allowing us to take a focused look into the most elite HBCUs in 1976 and 1989. Although there are important limitations with each of these data sets, together they provide a rich portrait of the causes and labor market and non-labor market consequences of HBCU attendance. Importantly, these data sets sample college matriculates in the 1970s and 1990s so it is possible to assess how these causes and consequences changed during these two decades of dramatic social change.

The analysis uses four separate statistical approaches to adjust for pre-college differences between HBCU and TWI attendees. We begin by using the rich set of covariates on family background and high school academic achievement (including SAT scores) to fit least squares models. We then use the same pre-college covariates to implement a propensity-score matching estimator to assess the robustness of the results to functional form assumptions about the observables. These approaches are supplemented by methods that are designed to account for selection bias due to missing outcome observations (Heckman 1979) and bias which emerges when colleges admit students based partly on characteristics unobserved in our data that are positively correlated with future outcomes (Dale and Krueger 2002).

The results are robust across these four methods. However, lacking a randomized experiment or credible quasi-experiment, thorny issues of selection may remain. Consequently, we urge caution in interpreting the results as causal.

Together the nationally representative NLS and B\&B reveal an important change in the returns to HBCU attendance. In the 1970s, HBCU matriculation was associated with higher wages and an increased probability of graduation, relative to attending a TWI. By the 1990s, however, there is a substantial wage 
penalty. Overall, there is a $20 \%$ decline in the relative wages of HBCU graduates in just two decades. Interestingly, relative pre-college measures of student quality (SAT scores, e.g.) improved among HBCU attendees during this period, so higher achieving students were increasingly choosing these schools at the same time that the returns for attending these schools were falling behind.

The underlying source of the decline in HBCU performance is unlikely to be important for policy reasons, given the high court's stance. Nevertheless, understanding it would be of considerable interest to researchers and educational practitioners. The data fail to contradict, and in at least one specification support, the possibility that HBCUs' relative decline is partially due to improvements in TWIs' effectiveness at educating blacks. In contrast, the data contradict a number of intuitive explanations for the decline in outcomes among HBCU attendees-for example, educational expenditures per student increased more at HBCUs than at TWIs between the 1970s and 1990s.

The $\mathrm{C} \& \mathrm{~B}$ provides a rare opportunity to assess the most elite colleges. Here too, there is evidence of a wage decline between the 1976 and 1989 cohorts but it should only be considered suggestive because these estimates are imprecise. There is stronger evidence that the later HBCU matriculates were less satisfied with their choice of college and self-reported developing fewer leadership and social skills that are valuable in post-college life, relative to TWI students. On the other hand, the later cohort was significantly more likely to be involved in political, social, and philanthropic activities.

The paper proceeds as follows. Section II provides a brief history of HBCUS and their important role in the education of blacks in America. Section III reviews some theoretical explanations for why blacks might benefit (or be harmed) by attending a historically black college or university. Section IV presents the data and summary statistics. Sections V and VI report results on the causes and consequences of HBCU attendance. Section VII summarizes the differences between the results from the 1970s and 1990s and assesses alternative explanations for these differences. Lastly, Section VIII concludes. A data appendix describes the details of our sample construction.

\section{A Brief History of Historically Black Colleges and Universities}

\section{A. Ante-Bellum Period}

The 1860 Census counted 4.4 million Black people in the United States, most of whom lived in the Southern states and were held as slaves. Prior to the end of the Civil War, teaching slaves to read or write was prohibited by law (or social custom) in many areas of the South. Still, there were three Black colleges founded before the Civil War: the Institute for Colored Youth (now known as Cheney University) was founded in Pennsylvania in 1837; Lincoln College in Pennsylvania, 1854, and Wilberforce College in Ohio, 1856. All of these universities served secondary and post-secondary students. Formal education for most blacks would not become available until after the Civil War, when 
the Freedmen's Bureau, black communities and their churches, and private philanthropists organized schools for Blacks (Donohue, Heckman, and Todd 2002).

\section{B. Post-Civil War and the Second Morrill Land Grant}

During the period immediately following the Civil War, there was a dramatic increase in the number of educational institutions geared toward blacks, funded primarily through groups like the American Missionary Association, the Freedmen's Bureaus, and southern state governments, especially during the Reconstruction period. Between 1865 and 1890, over two hundred private black institutions were founded in the south. Very few of these early institutions awarded bachelor's degrees. The American Missionary Association, the Freedmen's Bureaus, and other groups that were active in the early education of freed blacks played a large role in establishing some standard of education - most notably literacy - that would be important when degree granting institutions for Blacks opened en masse in the 1890s.

Most public HBCUs trace their history to the second Morrill Act, passed in August 1890. In the next decade, 16 HBCUs opened their doors. The Morrill Act allowed for the creation of a two-tier system of land grant universities, with southern and border states creating HBCUs principally to gain access to federal funds to develop white land grant colleges. These HBCUs were largely limited to vocational training; well-known agricultural, mechanical, and technical institutions such as North Carolina A\&T and Florida A\&M were founded during this period.

By 1895, public HBCUs had awarded 1,100 college diplomas to black students. Yet, liberal arts education, as was offered at many public white institutions, remained unavailable to black students. During the Jim Crow era in the south that followed Reconstruction, educational opportunities for white students expanded and blacks were almost completely excluded from white institutions.

In the 1896 decision, Plessy v. Ferguson (163 U.S. 537 (1896)), the two-tier system of higher education, based on the incentive structure in the Second Morrill Act, became more firmly set. As a result, HBCUs began to become institutions that primarily trained teachers to teach in segregated public schools. The rapid expansion of black high schools in southern urban areas set in motion a supplydemand chain in which availability of teaching positions, supported by state treasuries, drew more black students into HBCUs to qualify themselves for teaching positions (Roebuck and Murty 1993). There became an interdependence between the public school system and HBCUs.

\section{World War II and the Higher Education Act of 1965}

HBCUs, as well as other institutions of higher learning, faced a funding crisis in the 1940s due to the budget cuts in educational funding associated with WWII. In 1944, the United Negro College Fund 
was established, raising $\$ 765,000$ for HBCUs in its first funding campaign; three times as much as had been raised by the individual colleges in the previous three years.

The landmark decision in Brown v. Board of Education (349 U.S. 294 (1955)) and the legislation developed to implement it improved the plight of many HBCUs. Title III of the Higher Education Act of 1965, which was devoted to "Strengthening Developing Institutions" was interpreted as primarily referring to HBCUs. As a result many HBCUs benefited greatly from the federal funds provided under Title III, funds that could be used for faculty and student exchanges, faculty improvement programs, curriculum improvements, student services, visiting scholars programs, and administrative improvements.

Despite the material gains to the HBCUs arising under the Higher Education Act, the NAACP continued a legal strategy of attacking the two-tier educational system, asking the U.S. Department of Health, Education, and Welfare to enforce the Civil Rights Act of 1964 and prohibit southern states from operating a segregated higher education system. In the 1973 case of Adams v. Richardson (356 F. Supp. 92 ( D.D.C.), modified and aff'd, 480 F.2d 1159 (D.C. Cir. 1973)), the NAACP won, requiring that states develop desegregation strategies that would allow for a better racial mix of students, faculty, and staff in public colleges, and increase the access and retention of minorities at all levels of higher education. The ruling was primarily aimed at non-HBCUs, however, and the court made it clear that fulfilling the ruling's mandate should not be accomplished at the expense of or detriment to traditionally black colleges

The Adams decision increased funding for HBCUs because the decision stated that states could not meet their mandates by closing HBCUs and that they must instead include "yardsticks" to measure the improvement of black colleges' facilities as well as their academic programs. The court's reasoning was that this was the only way possible to ensure that HBCUs would become desirable institutions for white students.

\section{The Unintended Consequences of U.S. v. Fordice}

On June 26, 1992, the Supreme Court decided U.S. v. Fordice, a decision brought by a black litigant with the chief aim of removing structural differences between HBCUs and traditionally white institutions. The plaintiff, represented by the NAACP, brought the suit because of the disparity in the number and quality of the academic programs, instructional staff, and physical plant facilities, arguing that this resulted from the "historically operated racially segregated dual systems of higher education." The court ruled that it would be wasteful to maintain the two-tier system that had been erected during an era of de jure segregation, noting that Mississippi had eight institutions, five white and three black, and that four of them (two white and two black) were within 25 miles of one another. The decision was a victory for civil rights lawyers, ordering Mississippi and 18 other southern states to do more to integrate its HBCUs and traditionally white institutions. 
However, the ruling had an adverse effect on HBCUs because the court ordered state legislatures to find "educational justification for the continued existence" of the two parallel education systems. The consequences of this ruling for the future of HBCUs is unclear at this point, but at least three outcomes seem possible: 1) a decision that HBCUs are indispensable for the education of Blacks and an increase in public funding; 2) increased recruitment and matriculation of white students, which has the potential to undermine the unique mission and culture of these institutions; and 3) a decision that they no longer are necessary (or as necessary) and a commensurate reduction in public financial support.

The remainder of the paper assesses empirically the causes and consequences of attending HBCUs, which will help determine their "educational justification."

\section{Conceptual Framework}

There are at least three theories for why blacks would benefit from racial segregation of institutions of higher education. First, Tatum (1997) argues that racial grouping is a developmental process in response to racism. This argument goes that segregation by race is a positive coping strategy that allows individuals to gather support through shared experiences and mutual understanding. Second, Wilson's (1987) pioneering study of the South Side of Chicago argues that the migration of talented blacks from black neighborhoods had adverse effects on the individuals left behind. A similar phenomenon may exist for segregation across schools - low ability blacks may benefit from segregation through more intensive interactions with their high ability peers. Third, segregated social connections within schools may also reduce adverse peer interactions resulting from interracial contact. Fryer with Torelli (2006) shows that racial differences in the social price for academic achievement are exacerbated in environments with more interracial contact.

There are also several theories for why racial segregation across colleges and universities may harm blacks. A well developed literature emphasizes the importance of peer groups (Coleman 1966), social interactions (Case and Katz 1991, Cutler and Glaeser 1997), and network externalities (Borjas 1995, Lazear 1999), especially for youths. Many argue that these effects are important in the formation of skill and values and the development of human and social capital. Moreover, segregation across schools may lead to the development of an "oppositional culture" and the enforcement of other negative behavioral norms (Ogbu 1989). Additionally, segregation across schools can prevent positive spillovers between racially defined peer groups (Lazear 1999).

A final disadvantage of the separation of racial groups across universities concerns the importance of interracial contact in mediating stereotypes and promoting understanding and tolerance. Interracial interaction generally leads to positive sentiment (Homans 1950), and fosters the creation of "bonding" and "bridging” capital (Granovetter 1973, Putnam 2000) 
It is impossible to identify the separate impact of each of these channels on segregated Blacks' well being with the available data sets. Instead, this paper's goal is to produce reliable estimates of the net impact of HBCU attendance. The resulting "reduced form" estimates will likely reflect a number of the channels specified in this section.

\section{Data Sources and Summary Statistics}

We analyze three large datasets: The National Longitudinal Study of the High School Class of 1972 (NLS-72), Baccalaureate and Beyond Longitudinal Study (B\&B), and the College and Beyond (C\&B) database. These data sets have been chosen because of the enormous amount of information each contains on pre-college academic performance, family background, college entry decisions, performance while in college, and later life outcomes. ${ }^{3}$ Throughout the analysis, the rich set of pre-college and family background variables are used as conditioning variables to adjust for observable differences between HBCU and non-HBCU matriculates in equations for the other variables. We discuss each of these sources and present summary statistics from them.

Before proceeding to this material, Appendix Table 1 provides some summary statistics on the 89 4-year historically black colleges and universities in the United States. Forty-nine of them are private institutions. They are predominantly located in the South. Together their undergraduate enrollment in the Fall of 2005 was 238,911 and there were an additional 37,151 graduate students enrolled. The fourteen historically black 2-year colleges are not included in this table.

\section{A. The National Longitudinal Survey of the High School Class of 1972}

The National Longitudinal Survey of the High School Class of 1972 (NLS-72) is a nationally representative sample of 23,451 high school seniors in 1972. Participants in the sample were selected in the Spring of 1972, and in a supplementary sample drawn in 1973. The data include a base year survey, and follow-up surveys in 1973, 1974, 1976, 1979, and 1986. Roughly 1,300 high schools are included in the sample, with an average of 18 students per school in the study.

A wide range of data is gathered on the students in the study, as described in detail at the NLS-72 website (http://nces.ed.gov/surveys/nls72). There is detailed information on each student's family environment, parent's education and occupation, socio-economic status, and the pre-college characteristics of each student (i.e. high school grades, college admission scores, and so on). There are also detailed records from post-secondary transcripts, collected in 1984, and high school records.

\footnotetext{
3 Two other data sets collected by the National Center for Education Statistics, the National Educational Longitudinal Study 2000 (NELS) and the Beginning Postsecondary Study (BPS), are equipped to answer some of the questions posed here. Unfortunately, however, these data sets do not track individuals long enough after college completion to be useful for understanding later life outcomes.
} 
Important for our purposes, a six digit identification number was assigned to educational institutions by the Federal Interagency Committee on Education (FICE) to, historically, distinguish postsecondary schools that qualified as institutions of higher learning from those that did not. These codes are crucial in defining HBCUs and ensuring that this definition is consistent across data sets.

\section{B. Baccalaureate and Beyond}

The Baccalaureate and Beyond Longitudinal Study $(B \& B)$ is a nationally representative sample of 11,192 degree completers from 648 American colleges and universities in the 1992-1993 academic year. To identify a random sample of degree completers, B\&B uses the National Postsecondary Student Aid Study as a basis. The National Postsecondary Student Aid Study is a large nationally representative sample of colleges and universities, students, and parents.

A considerable amount of data is gathered on the students in the study, as described in detail at the B\&B website $h t t p: / / n c e s . e d . g o v / s u r v e y s / b \& b$. It contains detailed information on pre-college characteristics of each student, information about their parents and home environment, and financial aid information. Follow-up surveys were administered in 1994, 1997, and 2003. These follow-up surveys include information on employment and entry into graduate school. We focus on the responses to the 1997 survey, which takes place after most students are in the workplace. We had hoped to use the 2003 data more extensively, but we found it to be of generally poor quality on the dimensions we cared most about. For example, $25 \%$ of the original black respondents attrited from the 2003 sample, compared to just $6 \%$ in the 1997 sample. And, this attrition was largely from black students in TWIs.

There is one important difference between the B\&B and the other data sets we employ. The NLS and $C \& B$ begin with samples of students that enrolled their freshman year. The B\&B samples degree completers, which can introduce bias if graduation rates between HBCUs and non-HBCUs differ substantially. Whenever the results from this survey differ with our other data, we will be clear about whether this difference can be accounted for by differences in samples. A convenient way to handle this is to restrict the sample in our other data sets to be of degree completers, which we do throughout.

\section{The College and Beyond Database}

The College and Beyond Database contains student level administrative data on on 93,660 fulltime students who entered (but did not necessarily graduate from) thirty-four colleges and universities in the fall of 1951, 1976, and 1989. These institutional records were linked to an extensive survey conducted by the Andrew W. Mellon Foundation between 1995 and 1997 and to files provided by the College Entrance Examination Board and the Higher Education Research Institute. There are four HBCUs in the database: Xavier, Morehouse, Spellman, and Howard - the most elite HBCUs. The 1976 cohort contains 
data on all four black colleges; the 1989 cohort only includes Morehouse and Xavier. ${ }^{4}$ The final data set consists of black students from 34 colleges and universities including the four elite HBCUs; the sample consists of 2,125 students in 1976 and 1,785 in 1989.

The C\&B data are remarkably rich, containing information drawn from students' applications and transcripts, Scholastic Aptitude Test (SAT) and American College Test (ACT) scores, as well as information on family demographic and socioeconomic status. This information was attained by linking the institutional files of the thirty-four colleges and universities with data provided by the College Entrance Examination Board and the Higher Education Research Institute. Importantly, the C\&B survey includes the responses to a questionnaire administered to all three cohorts in 1996 that provides detailed information on post-college labor market, life satisfaction, and other outcomes. The response rate to the 1996 questionnaire was approximately 80\%. The College and Beyond Survey is described in greater detail in Bowen and Bok (1998).

\section{Summary Statistics}

Summary statistics for the variables in our core specification are displayed in Table 1 for black students in the three datasets described above, according to whether or not they attend a HBCU or TWI. Students who are missing data on race or which college they attended are dropped from the sample.

Table 1 consists of five sets of columns. The first column provides summary statistics for students in the NLS-72 whose first college was an HBCU versus TWI, where first college is defined as the first 4year college a student attends. An individual who attends a junior college, technical school, or the like and then attends an HBCU will be counted as having his first college as an HBCU. The second column restricts the sample to those who completed a bachelor's degree, allowing one to make direct comparisons with B\&B whose descriptive statistics are displayed in column 3. Columns 4 and 5 provide means of the variables for students in the C\&B database for the 1976 and 1989 cohorts, respectively. ${ }^{5}$

Across all our datasets, blacks attending TWIs tend to have substantially higher academic credentials. In the NLS-72, SAT and ACT scores of Blacks in TWIs are roughly 1 standard deviation higher. Yet, Blacks attending HBCUs have slightly higher GPAs than their peers who attend TWIs (2.86 compared to 2.83), suggesting that these students attend less academically challenging high schools. Students in HBCUs are more likely to attend private high schools. Similar trends are apparent in the $\mathrm{B} \& \mathrm{~B}$, though the differences in academic credentials between HBCU students and non-HBCU students are less pronounced. A portion of the difference between the NLS-72 and B\&B can be explained by the

\footnotetext{
${ }^{4}$ All forthcoming results have been run by restricting the 1976 cohort to Morehouse and Xavier to ensure that any differences which emerge cannot be explained by different samples in the two cohorts.

${ }^{5}$ The C\&B 1976 data used to construct the summary statistics in Table 1 contains all 4 HBCUs available.
} 
different sample restrictions.

In the 1976 and 1989 cohorts of C\&B, the GPAs of Black students in HBCUs are .73 and .5 standard deviations less, respectively. SAT and ACT scores of HBCU students are more than 1 standard deviation behind Black students in non-HBCUs. In these data, students who attend HBCUs are less likely to have attended a private high school.

The "Pre-College Personal and Family Background" variables provide measures for the home environments that students were reared in. These variables include family income (measured in 1972 dollars), parental education, or whether or not a student attended high school in a rural area or the southern portion of the US. The definition of income differs slightly between data sets. In NLS-72, students were asked, "What is the approximate income before taxes of your parents (or guardian)? Include taxable and non-taxable income from all sources." For B\&B, we used family income in 1991 for students that were dependents of their parents and the student's own taxed and untaxed income for students that were not dependents. ${ }^{6}$ For C\&B, family income is derived from the HERI student survey. The CPI-U was used to convert all income measures to 1982-84 dollars.

It is apparent that there are important observable differences between blacks who attend HBCUs and TWIs. The subsequent analysis uses a variety of statistical approaches to adjust for these differences.

The third panel reports on many of the outcome variables. These include wages, major choice, whether or not a student received their bachelor's degree, attended graduate school, or obtained a graduate degree, and variables designed to measure college experiences and job and life satisfaction. In the raw data, blacks who attend HBCUs tend to make less money than blacks who attend TWIs, with one exception; NLS-72. ${ }^{7}$ They are also less likely to be employed full-time and more likely to be dissatisfied with life. HBCU students are more likely to major in physical sciences.

In the two nationally representative samples, black students at HBCUs are more likely to receive a bachelor's degree and attend graduate school (though they are less likely to graduate). Black students in the elite HBCUs are more likely to major in biological sciences (this is driven in large part by Xavier who has a storied reputation for pre-medical studies), business, less likely to receive a bachelor's degree or attend graduate school, and, in the 1989 cohort, less likely to report that their college experience helped

\footnotetext{
${ }^{6}$ For students who were their parents' dependents in 1991, total family taxed and untaxed income was obtained, in order of priority, from the student's financial aid application, a telephone interview of parents, a telephone interview of the student, the student's Pell grant file, or the student loan file. For students that were not their parents' dependent, the information was obtained, in order of priority, from the financial aid application, the student's phone interview, the student's Pell grant file, or the student loan file.

${ }^{7}$ In the NLS-72, the average hourly wage is $\$ 12.82$ (\$14.46) for HBCU attendees (graduates) and $\$ 10.55$ (\$11.38) for TWI attendees (graduates). The mean of the natural logarithm of hourly wages is about $5 \%(12 \%)$ higher for TWI attendees (graduates). The difference in the rank of wages across HBCUs and TWIs is due to a single HBCU respondent with an average hourly wage of $\$ 494$. The influence of this observation on the Table 1 entries is also evident in the larger standard deviation of wages among HBCU attendees and graduates. See the Data Appendix for details on the sample selection rules.
} 
develop an ability to get along with individuals of other races.

The final panel in Table 1 provides the total number of HBCU and TWI observations in each sample. It also provides some details on the incomplete observations. As a solution to the large number of observations with at least one missing variable, we turn all of the explanatory variables into a series of indicator variables based on ranges of the values of these variables and include separate indicators for missing responses to each variable. The bottom panel also reports on the number of observations with missing wage information. The subsequent analysis implements a standard selection correction approach to account for these cases (Heckman 1979).

\section{The Causes and Consequences of Attending HBCUs in the NLS and B\&B Data Files}

\section{A. The Causes of Attending HBCUs}

Table 2 presents a series of estimates of the determinants of HBCU attendance. The specifications estimated are of the form:

$$
\mathrm{HBCU}_{\mathrm{i}}=\alpha+\beta \mathrm{X}_{\mathrm{i}}^{\text {home }}+\gamma \mathrm{X}_{\mathrm{i}}^{\text {pre-college }}+\varepsilon_{\mathrm{i}},
$$

where HBCU is a dichotomous variable that equals one if the student attends an HBCU and zero if not, $X_{i}{ }^{\text {home }}$ denotes an array of variables which proxy for a student's home environment, and $X_{i}^{\text {pre-college }}$ denotes pre-college characteristics of each student. In all instances, weighted Probit regressions are used and the coefficients reported are marginal effects evaluated at the sample mean. The weights are the sample weights in the relevant data file. The interpretation of any coefficient is the effect of that coefficient relative to the omitted category when all other variables are held at their sample mean.

The home environment variables that we include are family income, mother and father's education, and whether or not a student lives in the South. Family income, measured in 1972 dollars, is divided into 4 categories: $<\$ 3,000, \$ 3000-\$ 6000, \$ 6000-\$ 9000$, and $\$ 9000+$ based on a survey question described in the previous section. Parental education (mother and father, independently) is partitioned into three categorical variables: less than a Bachelor's degree, a Bachelor's degree, and greater. Whether or not a student lives in the South is a dummy variable that takes on the variable of one if the answer is yes. Pre-college characteristics include SAT and ACT scores, high school GPA, and whether or not a student attended a private high school. Combined SAT scores are divided into less than 600, between 600-800, and greater than 800. ACT scores are divided up similarly, less than 11, between 11 and 15, and greater than 15. High school GPA is measured on a four point scale and is divided into less than 2.5, 2.5 to 3.5, and greater than 3.5. We also include an indicator for whether the respondent is female.

In 1972, students who attend HBCUs have lower SAT and ACT scores and are more likely to attend high school in the South. Moving from an SAT score below 600 to a score above 800 reduces the 
probability of attending an HBCU by 32\%. Similarly, moving from an ACT score of less than 11 to a score of more than 15 reduces the likelihood of attending an HBCU by $21 \%$. Students who live in the South are $43 \%$ more likely to attend HBCUs, holding all else constant. Family income and parental education are not statistically related to $\mathrm{HBCU}$ attendance once our other covariates are taken into account.

In the 1990s, things change. Standardized test scores are no longer such a powerful predictor of HBCU attendance. Parents with more education are more likely to have children who attend HBCUs. All else equal, a student whose mother has more than a bachelor's degree is $28 \%$ more likely to attend an HBCU. This is not surprising, as these institutions have a long history of loyal alumni and familial legacies (Drewry and Doermann 2001). Residing in the South continues to be an important determinant of college choice, though the magnitude of the coefficient is roughly a fourth of the magnitude in the seventies. Private high school is negatively correlated with HBCU attendance.

There are marked differences between the determinants of HBCU attendance in the 1970s and 1990s. The most obvious explanation of these differences is that conditioning on degree completion selects for high ability students and among this set, differences between the two periods will disappear. Comparing columns 2 and 3 in table 2 we can make direct comparisons between the 70s and the 90s; each sample consists only of degree completers.

Intuition suggests that as resistance to black attendance at TWIs faded and the need for segregated schooling declines, those with the highest opportunity cost of such schooling will opt out and choose more traditional universities. In other words, it might be reasonable to expect a "brain drain" from HBCUs. Yet, the data show the opposite to be true. Lower academic credentials are not as highly predictive of HBCU attendance in the 1990s as the 1970s. Students with higher educated parents are more likely to attend HBCUs in the 1990s and higher academic credentials are not as strong a predictor of nonHBCU attendance. This provides evidence of a selection of talented Black students into HBCUs in recent years.

\section{B. Econometric Approach to Estimating the Consequences of Attending HBCUs}

In the absence of a randomized experiment or a credible instrumental variable for $\mathrm{HBCU}$ attendance, we implement four statistical approaches to adjust for pre-college differences between HBCU and TWI attendees. This subsection details these strategies.

The first and simplest model we estimate is a linear specification of the form:

$$
\text { outcome }_{i}=\beta_{0}+\beta X_{i}{ }^{\text {parents }}+\alpha X_{i}^{\text {pre-college }}+\delta H B C U+\varepsilon_{i} .
$$

In all instances, the estimation is done using weighted least squares, with weights corresponding to the sample weights provided in the data. Equation (2) is a simple and easily interpretable way to obtain 
estimates of the effect of HBCU attendance on outcomes, but it relies on a linear model to control for the covariates $X_{i}^{\text {parents }}$ and $X_{i}^{\text {pre-college }}$. This may be unappealing since their true functional form is unknown.

As a solution, we match HBCU and TWI students with similar predicted probabilities or propensity scores (p-scores) of HBCU attendance (Rosenbaum and Rubin 1983). ${ }^{8}$ The estimated p-scores compress the multi-dimensional vector of covariates into an index. The advantages of the propensity score approach are twofold. First, it is a feasible method to control for observables in a more flexible manner than is possible with linear regression. Second, it provides an opportunity to focus the comparisons of outcomes between the HBCU and TWI attendees among those with similar distributions of the observables. Since we model all of the covariates with indicator variables the former advantage is not so compelling in this setting, but the latter is a real asset here. Finally, it is important to emphasize that just as with linear regression, the identifying assumption is that assignment to the treatment (i.e., HBCU attendance) is associated only with observable pre-period variables. This is often called the ignorable treatment assignment assumption or selection on observables.

We implement the p-score matching strategy in three steps. First, the estimated p-scores are obtained by fitting probit regressions for $\mathrm{HBCU}$ attendance (identical to equation 1 above), using $X_{i}^{\text {parents }}$ and $X_{i}^{\text {pre-college }}$ as explanatory variables. In other words, we try to replicate the average student's selection rule with the observed covariates. We then conduct two tests to ensure that the p-scores are suitable. For both tests, we divide the sample into quintiles based on their p-scores. In the first test, we assess whether the estimated p-scores are equal across the HBCU and TWI students within quintiles. In the second test, we examine whether the means of the covariates are equal for the two sets of students within each quintile. If the null hypothesis of equality is rejected for either test, we divide the qunitiles and /or estimate a richer probit model by including higher order terms and interactions. ${ }^{9}$ Once the null is accepted for both tests, we proceed to the next step.

Second, the "treatment effect" for a given outcome is calculated by comparing the difference in the outcome between HBCU and TWI students with similar or "matched" values of the p-score. We do this in two ways. The first calculates a treatment effect for each HBCU student for which there is at least one TWI student with an estimated p-score within 0.10 of the HBCU student's p-score. In cases where multiple students have p-scores within 0.10 , we take the simple average of outcome across all of these students. Further, this matching is done with replacement so that individual TWI students can be used as

\footnotetext{
${ }^{8}$ An alternative is to match on a single (or possibly a few) crucial covariate(s). See Angrist and Lavy (1998) or Rubin (1977) for applications.

${ }^{9}$ See Dehejia and Wahba (2002) and Rosenbaum (1984) for more details on how to implement the propensity score method.
} 
controls for multiple HBCU students. ${ }^{10}$ The second matching approach uses all of the TWI students to form a control for each HBCU student but in calculating the average among them we use a kernel weighted average, where the weight is inversely proportional to the distance to the HBCU student's pscore. We use a Gaussian kernel with a bandwidth of 0.10 .

Third, a single treatment effect is estimated by averaging the treatment effects across all HBCU students for which there was at least one suitable match. This approach has the desirable property that it focuses the comparisons where there is overlap in the distribution of propensity scores among the HBCU and TWI students so these students are "similar."11

We also implement two other econometric approaches to account for potential selection issues. First, we estimate probits for whether the wage variable is missing on the sample of observations with missing and non-missing wage values. We then include the inverse Mill's ratio from these probits in equation (2) to account for the possibility that wages are not missing at random (Heckman 1979). This procedure is identified from a functional form assumption, since we are unaware of a valid exclusion restriction in this setting.

Second, the available data sets may not include measures of some attributes (e.g., strength of essay, motivation, and teacher recommendations) that persuade admissions committees to select certain applicants for admission that are also rewarded in the labor market. Further, these attributes may differ across HBCU and TWI students. The least squares and propensity score approaches rely on "selection on observables" assumptions and will produce biased estimates in this case.

To confront this source of misspecification, we implement a variant of the method pioneered by Dale and Krueger (2002) that matches students based on the colleges where they were accepted. This approach can only be implemented with the NLS data file, as B\&B does not contain information on the sets of colleges to which individuals are admitted. We operationalize the Dale and Krueger approach by determining the identity of the colleges that accepted each student. Among the colleges where they were accepted, we find the midpoint of the 25th-75th percentile SAT range reported in US News \& World Report (2006). We use current SAT scores since scores from 1972 are unavailable. For colleges that report only ACT scores, we use an equivalence scale to convert to SAT scores.

For each student, we record the highest midpoint SAT score of any college that accepted the student. We divide the students into four groups by quartiles of the school with the highest midpoint SAT among the schools where they were admitted. We then include separate indicators for each of these groups in equation (2). This approach mitigates the impact of any confounding due to characteristics

\footnotetext{
${ }^{10}$ See Dehejia and Wahba (2002) and Heckman, Ichimura, and Todd (1998) on propensity score algorithms.

${ }^{11}$ If there are heterogeneous treatment effects, this strategy produces an estimate of the average effect of the "treatment on the treated".
} 
observable to admissions officers that are not measured in the data set. Specifically, the identifying assumption is that after adjustment for the available covariates, the decision to attend a HBCU versus a non-HBCU within a quartile is "ignorable" or orthogonal to unobserved determinants of outcomes. See Dale and Krueger (2002) for a more detailed discussion of this approach.

Finally, we note that we considered a number of candidate instrumental variables, such as distance to a student's nearest HBCU, residing in the South, or the closing of HBCUs, but in all cases we were unconvinced that the exclusion restriction was valid or the instruments were not powerful enough for the relatively small samples in the available data files. With approximately 300 observations, it is very difficult to construct an instrument with a powerful first stage. Consequently, thorny issues of selection may still remain.

\section{Estimates of the Consequences of Attending HBCUs}

Distribution of Estimated P-Scores. Figures 1 and 2 present separate kernel density plots of the estimated propensity scores for black students that received degrees from HBCUs and TWIs with the NLS and B\&B data files, respectively. To obtain these figures, weighted probits were estimated on the set of students who completed their bachelor's degree at an HBCU or TWI. In Figure 1, which is based on the NLS data, it is evident that the mean propensity score differs across the populations, but there is substantial overlap in the distributions, except at $\mathrm{p}$-scores exceeding roughly 0.9 . The distributions of $\mathrm{p}$ scores in the B\&B are more similar throughout a broader range of the p-score. However, there aren't any TWI students with p-scores greater than about 0.8 . Thus, it will be difficult to obtain meaningful comparisons for the relatively small subset of HBCU students with p-scores in this range.

Wage Outcomes. Table 3 presents results of the effect of attending a HBCU on the natural logarithm of wages from the four approaches in the six columns. The estimated standard errors are reported in parentheses below the point estimate for the HBCU indicator. In the NLS entries in Panels A and $\mathrm{B}$, the standard errors allow for clustering among observations from students that attended the same high school (except in column 5). In Panel A, the treatment is matriculation at a HBCU, while it is graduation from a HBCU in Panel B. For the B\&B entries in Panel C, we report standard errors that allow for unspecified heteroskedasticity in the variance-covariance matrix. Underneath the standard errors, we report the R-squared statistic, as well as the number of students in HBCUs and TWIs in the relevant sample. For the NLS, wages are measured in 1986 - fourteen years after high school graduation and roughly 10 years after obtaining a bachelor's degree. In the B\&B, wages are in 1997, five years after completion of the bachelor's degree.

Column 1 reports the mean difference in labor market wages for individuals who attend HBCUs, without adjustment for any controls. In the NLS, HBCU students earn roughly $5 \%$ less when the 
treatment is the first college attended and $11.5 \%$ when it is receipt of a bachelor's degree. Neither of these estimates is statistically different from zero at conventional levels. The B\&B estimate from the 1990s indicates that HBCU graduates earn 16.6\% less than TWI graduates. Recall, Table 1 demonstrated that on observable dimensions HBCU students have lesser academic credentials than their TWI counterparts (especially in the NLS), so these raw gaps are likely downward biased.

Column 2 reports the results from estimating equation (2). The adjustment for the academic and home environment controls changes the results in the NLS dramatically. ${ }^{12}$ The wage benefit of attending a HBCU in the $1970 \mathrm{~s}$ is $11.1 \%$ when HBCU status is based on the first college attended and $6.0 \%$ when it is defined as receiving a bachelor's degree. The former estimate is marginally significant, while the latter has an associated t-statistic less than $1 .^{13}$ In the $\mathrm{B} \& \mathrm{~B}$, however, the wage effect for attending HBCUs is $-13.8 \%$ and the null of zero would be rejected with conventional criterion. ${ }^{14}$

The next two columns report on the implementation of the p-score method to test the sensitivity of these results to the linear model. Column 3 uses kernel matching, while column 4 relies on radius matching. ${ }^{15}$ Standard errors for both matching estimates were bootstrapped (200 iterations), with propensity scores recomputed for each bootstrap sample. Further, the p-score matching estimates are not weighted with the sample weights.

The p-score estimates are remarkably similar to those from the linear regression in column 2 . This finding shouldn't be terribly surprising because equation (2) models the covariates flexibly, nevertheless it is reassuring that functional form issues don't appear important in this setting.

Column 5 presents estimates that are selection corrected for missing wages and adjusted for the full set of covariates. It seems plausible that HBCU attendance is correlated with selective withdrawal from the labor force. This possibility is not supported by the data as this approach produces unimportant change in the estimated impact of HBCUs on wages. ${ }^{16}$

\footnotetext{
${ }^{12}$ A similar result was found in Constantine (1995).

${ }^{13}$ Results are similar if one implements a "fraction method," using individual transcripts to calculate the fraction of a student's college experience that was spent at an HBCU.

${ }^{14}$ In the most recent wave of the B\&B (B\&B 2003) there is no wage gap between HBCU students and non-HBCU students. Unfortunately, $53 \%$ of the HBCU sample does not have valid wages in the later survey (some are in the survey and unemployed while others were dropped completely). HBCU graduates have a 9.6\% higher unemployment rate, and median regression techniques provide identical results to the 1997 wave. Thus, we concentrate on the earlier wave with more complete data.

${ }^{15}$ Observations with estimated p-scores that are not strictly between 0 and 1 are dropped. Further, we lose 7 observations in the NLS when the treatment is first college attended and 21 when the treatment is degree college, and 21 observations in the $\mathrm{B} \& \mathrm{~B}$ when implementing the radius matching estimators due to outliers that did not have matches in the relevant range.

${ }^{16} \mathrm{We}$ also assessed the impact of labor market dropouts on our estimates with a simple re-weighted linear regression and median regression. In the first approach, we estimate a probit of whether or not we have valid wages on all of the covariates in Table 2. We then multiplied the sampling weight by the inverse of the predicted probability in the probit to get new weights. Linear regressions are then estimated with these new weights. This approach led to remarkably similar conclusions as the selection correction approach. Median regressions were estimated by
} 
Column 6 implements the column 2 specification but adds controls for the "best" school that the student was admitted to in order to account for the richer data available to admissions committees (Dale and Krueger 2002). Specifically, we include indicators for the three highest quartiles of SAT scores of the best school that the student was admitted to, leaving the lowest quartile as the excluded group. This method is only possible in the NLS data and in this sample it doubles estimated impact of attending a HBCU to $22.5 \%$. Specifically, this approach suggests that the gains from HBCU attendance may be larger than indicated by the other methods. However, the estimate's imprecision makes definitive conclusions unwarranted.

Additionally, we conducted a number of tests for whether there was heterogeneity in the returns to attending a HBCU, which are reported in Appendix Table 2. We assessed whether returns differed with students' home region (i.e., South versus North), their estimated propensity score, SAT Score, parental education, and gender. In general, there isn't substantial evidence of heterogeneity across these subsamples of students. The lone exception is that the returns to attending a HBCU appear higher for black women than for black men in the NLS sample. It is also immediately evident that subdividing the sample is too demanding of the data as the standard errors in the subsamples are much larger.

Overall, these results suggest that attending an HBCU conferred remarkable advantages on its students in the 1970s. Conventional estimates of the average return to college are $10 \%$ per year (Heckman, Lochner and Todd 2003). Attending a HBCU versus a TWI in the 1970s was roughly equivalent to one more year of schooling. In contrast, more recent HBCU attendees appear to be suffering a wage penalty. If the point estimates are taken literally, there is nearly a $-25 \%$ swing in the relative return of $\mathrm{HBCU}$ attendance in just two decades.

Non-wage outcomes. Thus far we have concentrated on the effect of attending a HBCU on a single outcome: labor market wages. The value of attending HBCUs, however, likely extends well past labor market considerations. The conventional wisdom is that these institutions instill confidence in their students, a sense of responsibility, and provide environments free of racism and discrimination that allow for greater personal development. Such environments are likely to have many benefits beyond those captured in wages.

Table 4 explores the effect of attending HBCUS on a number of outcomes, including the probability of full-time employment, measures of life satisfaction, and a series of academic outcomes. These wide ranging outcomes were chosen because of their economic and social relevance as well as their comparability across datasets. The academic outcomes index is the first principal component of the dummy variables for majoring in business, majoring in physical science/mathematics/computer

imputing zeros to all missing wage observations. Qualitative conclusions were the same, though the coefficients were smaller as expected. 
science/engineering, majoring in biological science/health, receiving a bachelor's degree, attending graduate school, and receiving a graduate degree. The coefficients reported in the table are from kernel matching estimates and their associated bootstrapped standard errors. In all cases, weighted least squares confirm these results.

The most striking finding from these outcomes is that HBCU matriculation is associated with a nearly $10 \%$ increase in the probability of receiving a bachelor's degree. It is evident that part of the wage gain in the 1970s is due to the increased probability of graduating from college. There is some evidence that students who attend HBCUS are modestly more likely to major in physical sciences. Interestingly, HBCU and TWI matriculates report similar degrees of life satisfaction. There are negligible effects on all other outcomes.

\section{A Focused Look at the Most Elite HBCUs}

There is substantial quality variation among the set of 89 4-year HBCUs, as well as among the TWIs. To this point, we have analyzed the NLS and B\&B, which are nationally representative data files that include the full spectrum of HBCUs and TWIs from the quality continuum. In this section, we take a more focused look at four of the most elite HBCUs: Morehouse, Xavier, Spellman, and Howard. (Importantly, the 1989 data set does not include information on Spellman and Howard students.) One limitation of this exercise is that due to the C\&B's sampling approach, these four HBCUs can only be compared to the thirty selective TWIs in the sample.

Table 5 reports on the determinants of attendance for elite HBCUs for the 1976 and 1989 cohorts of C\&B from estimating equations identical to those in Table $2 .{ }^{17}$ Column (1) is a sample of individuals in all 4 HBCUs, column (2) drops Howard and Spelman so that we can make direct comparisons with the 1989 cohort which is displayed in column (3). The patterns across the columns are quite similar. The parameters on the standardized test scores are the most notable results. Evaluated at the sample mean, the difference between a SAT score of less than 600 and a SAT score above 800 implies a $40.1 \%$ decrease (column 2) in the likelihood of attending an elite HBCU in the 1976 cohort and a $63.1 \%$ decrease (column 3) in the 1989 cohort. ACT scores have a similar effect on HBCU attendance. Mother's education is positively associated with HBCU attendance in 1989. After adjustment for the academic characteristics, the income variables are not reliable predictors of elite HBCU attendance. Residing in the southern portion of the United States continues to be a strong predictor of HBCU attendance; increasing the probability of attendance by roughly $40 \% .^{18}$

\footnotetext{
${ }^{17}$ Throughout the C\&B analysis, the treatment is defined as enrollment at a HBCU, not graduation from one. For consistency with the other tables, we refer to the treatment as "first college", although due to the C\&B's sampling scheme it is possible (but unlikely) that a respondent was initially enrolled at a different college or university.

${ }^{18}$ The large negative coefficient on female in 1989 is related to the fact that the women's college Spellman is not in
} 
Figures 3 and 4 plot the distributions of the estimated propensity scores for the HBCU and TWI attendees from the 1976 and 1989 C\&B classes, respectively. Howard and Spelman were dropped from this analysis to make the samples consistent. It is apparent that there isn't substantial overlap across the two distributions in either year, especially in 1989. This finding confirms the impression from the probit results that the academic credentials of these students differ in important ways.

The poor overlap of the distributions poses challenges for the outcomes analysis. For example, in the propensity score exercise where we require the TWI students to have p-scores within 0.1 of the HBCU student, it is apparent that we will rely on a small subset of the data. In this subset of the data, the selection on observables assumption may be especially unlikely to be valid. On the other hand, we can use least squares functional form assumptions to infer counterfactuals in parts of the distribution where there is little support. Neither approach is especially appealing, which underscores the difficulties of inferring the impact of HBCU matriculation in this sample. Consequently, the forthcoming results should be interpreted with these important caveats in mind.

We now turn to an exploration of the effect of attending elite HBCUs on labor market outcomes, measures of life satisfaction, and academic outcomes from the 1976 and 1989 C\&B. One major benefit of the $\mathrm{C} \& \mathrm{~B}$ database is the availability of detailed questions about life outcomes, beliefs, college experiences, labor market outcomes and experiences, political and civic engagement, and more. These rich questions can help to shed light on the overall experience of students attending HBCUs and nonHBCUs. For both cohorts, data on the majority of outcomes was obtained in 1995, 15 years after graduation for the early cohort and 2 years after graduation for the later cohort, though some data such as wages in the 1989 cohort were collected in 1996. Individuals without valid wage observations are dropped from the sample.

Because the number of potential dependent variables in C\&B is so numerous, we construct five indices to better understand the experiences of HBCU students along the following dimensions: objective academic, subjective academic, labor market, leadership and lifestyle, and social interactions. The data appendix describes the specific questions used to make up these indices. Each index is obtained by taking the first principal component of the set of variables described. This approach has two main advantages. First, principal components analysis reduces the dimensionality of problems by extracting the portion of a set of variables that explain the most variance within the set. Second, it ensures that all variables are measured on the same scale. The cost is that the result's meaning isn't transparent and cannot easily be applied to different settings.

Table 6 reports the results of estimating the effect of HBCU attendance on our set of wage and non-wage outcomes from kernel matching, which can be compared to the results in column 3 of Tables 3

the 1989 sample. 
and 4. Column 1 includes all four HBCUs in the 1976 sample. Column 2 also reports results from the 1976 sample but only includes students who attended Morehouse and Xavier to facilitate comparisons with the 1989 cohort, whose results are reported in column 3.

In the 1976 cohort, HBCUs graduates were 9\% more likely to major in the biological sciences and $11.1 \%$ more likely to major in business, but $10 \%$ less likely to attend graduate school and, conditional on attending, 13.6\% less likely to receive a degree. On objective academic outcomes, HBCU students are significantly negative, though their subjective view of the academic experience is quite positive. Leadership and lifestyle components of the HBCU experience are large, which is consistent with much that has been written on these institutions (Drewey and Doerman 2001). Social interactions are also statistically significant and substantively large. The labor market experiences are positive, but negligible. Students do not seem to possess a particular taste for segregation, as HBCU graduates are no more likely to live in more racially homogenous zip codes. And, HBCU graduates are no more likely to be engaged in political, religious, civil rights, social service, or philanthropic activities. The clearest evidence of the importance of HBCUs is that, controlling for all other factors, HBCU students are $18 \%$ more likely to report they would choose the same college again.

The 1989 cohort reports different experiences. Students are more likely to major in physical and biological sciences and business. Students continue to benefit from leadership and lifestyle components of HBCUs, but the magnitudes of these effects are less than one-fourth of their previous levels. Many of the other positive elements turn negative in the more recent cohort. The objective and subjective academic outcomes are negative and HBCU matriculates are 10\% less likely to receive a bachelor's degree. The social interactions index, which was positive in the 1976 cohort, turns sharply negative in the 1989 cohort. The table demonstrates that this decline is also substantial in three of the variables that are used to construct the index in 1976 and 1989. The labor market experiences of the later cohort are even more negative, and they seem to have a taste for segregation. HBCU attendance is associated with living in a zip code that has a $16 \%$ higher fraction of blacks. Most telling, HBCU students are less likely than nonHBCU students to report they would choose the same college again, although the difference isn't statistically significant.

Interestingly, HBCU students in the later cohort are significantly more likely to be engaged in activities which are associated with civic consciousness. This may partly explain the divergence in wages. ${ }^{19}$

\section{Reconciling the Differences between the 1970s and 1990s}

\section{A. Assessing the Difference between the 1970s and 1990s Results}

\footnotetext{
${ }^{19} \mathrm{We}$ are grateful to Lani Gunier for pointing out this possibility.
} 
Panel A of Table 7 summarizes the difference in the results between the 1970s and 1990s. It reports regression results for five of the key dependent variables examined above. The difference is that we use the stacked 1970 and 1990 data sets to estimate the following equation:

$$
\begin{aligned}
\text { outcome }_{\mathrm{it}}=\quad & \beta_{0}+\gamma_{\mathrm{t}} \mathrm{X}_{\mathrm{it}}^{\text {parents }}+\alpha_{\mathrm{t}} \mathrm{X}_{\mathrm{it}}^{\text {pre-college }}+\lambda 1\left(\mathrm{HBCU}_{\mathrm{it}}\right)+\delta 1\left(1990_{\mathrm{it}}\right) \\
& +\theta 1\left(\mathrm{HBCU}_{\mathrm{it}}\right) \cdot 1\left(1990_{\mathrm{it}}\right)+\varepsilon_{\mathrm{it},}
\end{aligned}
$$

where the $i$ subscript indexes an individual and the $t$ subscript reveals whether the observation is from a 1970 s or 1990s college student. The parameter vectors $\gamma$ and $\alpha$ have $t$ subscripts indicating that they are allowed to differ for 1970s and 1990s college attendees. The equation also includes separate intercepts for attending a HBCU and whether the observation is from a 1990s college attendee. The parameter of interest is $\theta$, which is associated with the interaction between the HBCU indicator and the indicator for an observation from the 1990s. This parameter is a difference in differences (DD) estimate of HBCU attendance and is equal to the difference of the cross-sectional HBCU estimates (e.g., column 2 in Table $3)^{20}$

In column (1), the dependent variable is the natural logarithm of wages. For this regression, the nationally representative NLS and B\&B data files are used. The other seven dependent variables are taken from the 1976 and 1989 C\&B samples, which focused on a subset of elite HBCUs and TWIs. Howard and Spellman attendees are dropped from the sample, just as in column (2) of Table 6.

The results summarize the change in the relative returns to HBCU attendance over the two decades. The first four "objective" outcomes (i.e., those where a higher value of the dependent variable would be considered a positive) suggest that the returns to HBCU attendance have declined. Specifically, the point estimates suggest a $20 \%$ decline in wages, a $13 \%$ decline in the fraction of students who would attend the same college again, and substantial declines in the leadership and social interactions indices. The other three "objective" outcomes, which measure political participation, social/civic service, and donations to national charities, all show an increase between the two C\&B classes. The non-objective measure indicates that HBCU attendees became less likely to live in integrated neighborhoods. It is noteworthy that all of these estimates are economically and statistically significant.

\section{B. Robustness of the Result that HBCUs' Performance Worsened between the 1970s and 1990s}

This subsection reports on some checks that aim to explore the robustness of the basic result that the economic returns to attending a HBCU declined. Many obvious explanations fail to explain the differences. We have ensured, through the use of Federal Interagency Committee on Education codes, that the definition of HBCUs is consistent across data sets and over time. Moreover, the addition of more

\footnotetext{
${ }^{20}$ The C\&B results are not identical to the difference between the 1989 and 1976 results in Table 6 because that table reports on the kernel matching results, while Table 7 relies on least squares adjustment for the covariates.
} 
control variables, such as occupational choice indicators or a richer set of academic variables, fail to explain the differences. Further, differential labor market dropout rates cannot explain the change.

Selection of students into (or by) colleges is a potential explanation with some intuitive appeal, but the available data fail to support it. For example, Table 2 demonstrates that, if anything, selection on observables appears to work in the opposite direction. Students with higher scores on aptitude tests and better home environments are more likely to attend HBCUs in the 1990s, relative to the 1970s.

Nevertheless, we further explored the role of selection on observables. Specifically, we stacked the observations with non-missing wages from the NLS and B\&B and estimated a weighted probit for whether the observation was from the NLS (i.e., the 1970s). ${ }^{21}$ We then calculated the predicted probabilities that the B\&B (i.e., 1990s) observations are from the NLS. These predicted probabilities are multiplied by the sampling weight and this product is used as a weight in the fitting of the Table 3 column 2 OLS specification. This weighting scheme aims to ensure that the distribution of observables is similar across the NLS and B\&B. ${ }^{22}$

The result of this procedure is that the estimated impact of HBCU attendance on wages in the $\mathrm{B} \& \mathrm{~B}$ declines from $-13.8 \%$ (standard error of 0.050 ) to $-18.7 \%$ (standard error of 0.056 ). It is evident that this approach only increases the relative worsening of HBCU attendees' labor market performance between the 1970s and 1990s. Although we cannot rule out selection on unobservables, it seems reasonable to conclude that the results aren't due to differences in observable characteristics.

Another possibility is that due to the relatively small sample sizes, the quality of the HBCUs and TWIs represented in the NLS and B\&B differed. To explore this, we used US News and World Report (2006) to obtain the current midpoint of the 25th-75th percentile SAT range for all the HBCUs and TWIs represented by the valid observations in the data files. This information is only available for a subset of the observations. ${ }^{23}$ Nevertheless, these data indicate that the gap in average SAT scores between the HBCUs and TWIs chosen by the respondents in our analysis decreased between the two decades. Among the colleges and universities in our sample, SAT scores in TWIs were 236.1 points higher than HBCUs in the 1970s and 226.2 higher in the 1990s. Thus, the available evidence suggests that the results are not due to a change in the composition of HBCUs and TWIs between the NLS and B\&B.

\footnotetext{
${ }^{21}$ The weights are adjusted sampling weights, where the adjustment ensures that they sum to 1 within the NLS observations and within the $\mathrm{B} \& \mathrm{~B}$ observations. The covariates in the probit are the standard controls used throughout the paper (e.g., in column (2) of Table 3).

${ }^{22}$ This method is a variant of Dinardo, Fortin, and Lemieux (1996)

${ }^{23}$ We matched $92.3 \%$ of the HBCUs and $84.0 \%$ of the TWIs represented in the NLS. For the B\&B, these numbers were $88.9 \%$ and $82.7 \%$, respectively. Unfortunately, many of the colleges represented in these data files do not report SAT information in US News and World Report (2006). Specifically, we obtained SAT information for 29.2\% of the HBCU attendees and $49.0 \%$ of the TWI attendees in the NLS and for $33.0 \%$ of HBCU attendees and $49.2 \%$ TWI attendees in the B\&B.
} 


\section{Did HBCUs Decline or Did TWIs Improve?}

If the estimated decline is causal, the source of the relative decline in HBCUs' performance is unlikely to be important for public policy purposes. Nevertheless, it would be of considerable interest to researchers and educational practitioners to understand whether it is due to a decline in the performance of HBCUs or an improvement in TWIs. An answer to this question could lead to the design of more effective educational programs for blacks.

One potential explanation is that HBCUs' financial position weakened between the 1970s and 1990s leading to a decline in the quality of the educational environment at HBCUs. This explanation has some intuitive appeal, because HBCUs experienced enrollment declines in this period and Hoxby (2000) suggests that the nationalization of the higher education market has hurt smaller colleges and universities. However, the data don't appear to support this explanation. Specifically on a host of input measures, including financial information, faculty compensation, research grants received, and composition of faculty with various degrees, there is little evidence that the relative quality of HBCUs has declined in substantial ways (Provasnik, Shafer, and Snyder 2004).

Expenditures per student are perhaps the best measure of the quality of the education that these schools provided. Data on educational expenditures at HBCU and non-HBCU schools is available from the Higher Education General Information Survey from 1970-1984 and the Integrated Postsecondary Education Data System from 1985-2004 through the ICPSR web site. In 2000 dollars, educational expenditures per student increased from $\$ 9,423$ to $\$ 11,996$ between 1974 and 1991 at HBCUs and $\$ 8,468$ to $\$ 10,560$ at TWIs. ${ }^{24}$ (The years 1974 and 1991 are chosen, because they are roughly in the middle of the prime college attendance years of the students in the NLS and B\&B, respectively.) Put another way, real educational expenditures per student increased by $27.3 \%$ at HBCUs between 1974 and 1991, compared to $24.7 \%$ at TWIs. It is evident that data reject the hypothesis that the decline in returns to HBCU attendance is due to a decline in their quality as measured by expenditures. It is also notable that the level of education expenditures per student was greater at HBCUs in both the 1970s and 1990s.

An alternative explanation is that TWIs became more effective at educating blacks between the 1970s and 1990s in ways that aren't reflected in spending. After all, the 1970s are not far removed from the civil rights struggle, campus sit-ins and boycotts, and battles over even allowing black students to enroll in many Southern TWIs. Further, it has been noted that many TWIs were not convivial places for black students in the 1970s (Patton 2005). A related theory that is empirically indistinguishable is that society has changed so that there is a greater premium on cross-racial connections.

\footnotetext{
${ }^{24}$ Educational expenditures is the sum of expenditures made from the current funds that relate to the functions of instruction, research, public service, academic support, student services, institutional support, operation and maintenance.
} 
To explore this possibility credibly, it is essential to have a counterfactual for blacks' changing experiences at TWIs. After all, it is possible that TWIs became more effective educational institutions for all students between the 1970s and 1990s. We use whites' experiences at TWIs as a counterfactual in the following equation:

$$
\begin{aligned}
\text { outcome }_{\mathrm{it}}=\quad & \beta_{0}+\gamma_{\mathrm{rt}} \mathrm{X}_{\mathrm{it}}{ }^{\text {parents }}+\alpha_{\mathrm{rt}} \mathrm{X}_{\mathrm{it}}{ }^{\text {pre-college }}+\lambda 1\left(\text { Black }_{\mathrm{it}}\right)+\delta 1\left(1990_{\mathrm{it}}\right) \\
& +\theta 1\left(\text { Black }_{\mathrm{it}}\right) \cdot 1\left(1990_{\mathrm{it}}\right)+\varepsilon_{\mathrm{it}},
\end{aligned}
$$

where (again) the i subscript indexes an individual, the $t$ subscript reveals whether the observation is from a 1970s or 1990s college student, and $r$ references race. The vectors $\gamma$ and $\alpha$ have "rt" subscripts, indicating that they may vary by race, time period, or both. The equation also includes separate intercepts for black students and whether the observation is from a 1990 college attendee. The parameter of interest is $\theta$, which is associated with the interaction between the Black indicator and the indicator for an observation from the 1990s attendees. This parameter is a difference in differences (DD) estimator and reports on whether the returns for TWI attendance increased between the 1970s and 1990s for blacks, relative to whites. All HBCU attendees are dropped from the estimating samples in all specifications.

Panel B of Table 7 reports on the estimation of equation (4) for the natural logarithm of wages only, since this is the variable of interest available in the nationally representative data files. The column (1) specification constrains the $\gamma$ and $\alpha$ vectors to be constant across races and periods. The column (2) one allows them to differ across decades but holds them constant across whites and blacks within a decade (i.e., in the same survey). In column (3), they are allowed to vary across races but are restricted to be constant across decades.

The column (3) specification suggests that among TWI attendees, the wages of blacks increased by $13.4 \%$ more than wages of whites between 1970 and 1990 . This estimate is statistically significant and would account for roughly two-thirds of the relative decline in the wages of black HBCU attendees in Panel A. The point estimates are also positive in the other two specifications, but they are smaller and statistically indistinguishable from zero.

The difference in the results across the three specifications is due to the choices about the $\gamma$ and $\alpha$ parameter vectors. It is important to note that F-tests lead to rejections of the hypotheses that the parameter vectors are equal across decades (column 2) and race (column 3), so the column (1) specification is just too parsimonious. The R-squared statistic is largest in the column (2) specification but so is the standard error on the parameter of interest. We also experimented with a model that allowed the parameter vectors to vary with indicators for the interaction of decade and race, but the resulting estimates had little empirical content. ${ }^{25}$

${ }^{25}$ This model is too demanding of the data. Recall, all of our controls are indicator variables so issues of multicollinearity are an especial concern. As a measure of this problem, the standard error on the parameter of 
We are unaware of good reasons to favor either the column (2) or column (3) specifications, so we are left with two specifications that appear to have equal standing. One suggests that roughly twothirds of the decline in the relative wages of HBCU attendees is due to improvements in TWIs' efficacy at educating Blacks. The other produces an imprecise estimate that if taken literally implies that this explanation has little empirical backing. Both have confidence intervals with significant overlap. The sober conclusion is that the data fail to reject the possibility that TWIs became more effective at educating blacks between the 1970s and 1990s, but they also fail to provide decisive evidence in favor of this possibility.

\section{Conclusion}

Historically Black Colleges and Universities are an integral and proud part of Black history and culture. For generations, these institutions have educated Blacks and produced leaders in government, business, entertainment, and the academy. Yet, their reliance on public funding and the Fordice decision mean that it is more important than ever to understand the causes and consequences of matriculation at HBCUs.

Existing evidence on the effects of attending Historically Black Colleges and Universities has typically concentrated on either degree attainment or future wages. In this paper, we take a more holistic approach - analyzing three large data sets with adequate pre and post college information, a student's choice of college, and myriad social and economic outcomes to paint a rich portrait of the experiences of black students at Historically Black Colleges and Universities, relative to their counterparts who choose to attend non-HBCUs now and over time. Consistent with the charge from the high court, we search for "educational justification."

Several important results from this search have emerged. The nationally representative datasets reveal an important change in the returns to HBCU attendance. In the 1970s HBCU matriculation was associated with higher wages and an increased probability of graduation, relative to attending a TWI. By the 1990s, however, there is a substantial wage penalty. In fact, there is a statistically significant $20 \%$ decline in the relative wages of HBCU graduates between the two decades. Notably, relative measures of student quality (e.g., SAT scores) improved among HBCU attendees during this period, so higher achieving students were increasingly choosing these schools at the same time that the schools appear to have fallen behind. Finally, there is also some evidence of a relative decline in the performance of elite HBCUs from the College and Beyond.

The analysis has unearthed some important clues as to why HBCUs' relative performance declined in this period. The data provide some support for the possibility that HBCUs' relative decline is 
partially due to improvements in TWIs' efficacy in educating Blacks, but this evidence certainly isn't decisive. In contrast, the data reject a number of seemingly intuitive explanations, including relative declines in the pre-college credentials of students attending HBCUs and in educational expenditures per student at HBCUs. This question of why HBCUs' performance declined merits further research, although the identification of the exact channel is unlikely to be important for policy purposes.

In summary, the evidence presented in this paper suggests that relative to TWIs, HBCUs may have provided unique educational services for blacks in the 1970s. However by the 1990s, this advantage seems to have disappeared on many dimensions and by some measures HBCU attendance appears to retard black progress. 


\section{References}

Angrist, Josh and Victor Lavy. "Does Teacher Training Affect Pupil Learning? Evidence from Matched Comparisons in Jerusalem Public Schools.” Journal of Labor Economics, Vol. 19, 2 (Apr. 2001), 343-369.

Borjas, George J. Ethnicity, Neighborhoods, and Human-Capital Externalities. American Economic Review, June 1995, 85(3), pp. 365-90.

Bowen, William and Bok, Derek. 1998. The Shape of the River: Long Term Consequences of Considering Race in College and University Admissions. Princeton, NJ: Princeton University Press.

Case, Anne C and Katz, Lawrence F. "The Company You Keep: The Effects of Family and Neighborhood on Disadvantaged Youths." National Bureau of Economic Research (Cambridge, MA) Working Paper No. 3705, 1991.

Constantine, Jill. 1995. "The Effect of Attending Historically Black Colleges and Universities on Future Wages of Black Students.” Industrial and Labor Relations Review, Vol. 48, 3, 531-546.

Coleman, James S., et al. Equality of Educational Opportunity. Washington, D.C.: Government Printing Office, 1966.

Cutler, David M and Glaeser, Edward L. "Are Ghettos Good or Bad," Quarterly Journal of Economics, August 1997, 112(3), pp. 827-72.

Dale, Stacey and Alan Krueger. 2002. "Estimating The Payoff Of Attending A More Selective College: An Application Of Selection On Observables And Unobservables," Quarterly Journal of Economics, 2002, 107(4,Nov), 1491-1527.

Dehejia, Rajeey H. and Sadek Wahba. "Propensity Score-Matching Methods for Nonexperimental Causal Studies." The Review of Economics and Statistics. Vol 84, 1 (Feb. 2002), 151-161.

J. DiNardo, N. Fortin and T. Lemieux, 1996, "Labor Market Institutions and the Distribution of Wages, 1973-1992 : A Semiparametric Analysis”, Econometrica, Vol. 64, September, pp.1001-1044

Donohue, James Heckman, and Petra Todd. 2002. "Social Action, Private Choice, and Philanthropy: Understanding the Sources of Improvements in Black Schooling in Georgia, 1911-1960," The Quarterly Journal of Economics, 117(1), pp. 225-268

Drewry, Henry and Humphrey Doermann. 2001. Stand and Prosper: Private Black Colleges and Their Students. Princeton, NJ: Princeton University Press.

Ehrenberg, Ronald. “Are Black Colleges Producing Today's African American Lawyers?” The Journal of Blacks in Higher Education, 14(Winter 1996-1997), pp. 117-119.

Ehrenberg, Ronald and Donna Rothstein. 1994. "Do Historically Black Institutions of Higher Education Confer Unique Advantages on Black Students? An Initial Analysis.” In Choices and Consequences: Contemporary Policy Issues in Education, Ronald Ehrenberg, ed. Ithaca, NY: ILR 
Press.

Fordham, Signithia and Ogbu, John. "Black Students' School Successes: Coping with the Burden of ‘Acting White.” The Urban Review, 1986, 18, pp. 176--206.

Fryer, Roland G., Jr. with Paul Torelli. “An Empirical Analysis of `Acting White.” National Bureau of Economic Research (Cambridge, MA) Working Paper No. 11334, 2005.

Granovetter, Mark S. “The Strength of Weak Ties.” American Journal of Sociology, 1973, 78, pp. 136080.

Heckman, James. 1979. "Sample Selection Bias as a Specification Error”, Econometrica, 47(1), pp. 153161.

Heckman, James, Hidehiko Ichimura, and Petra Todd. "Matching as an Econometric Evaluation Estimator." Review of Economic Studies. Vol. 65, 2 ( 1998), 261-294.

Homans, George C. The Human Group. New York: Harcourt Brace, 1950.

Hoxby, Caroline. 2000. "The Effects of Geographic Integration and Increasing Competition in the Market for College Education,” NBER Working Paper No. 6323.

Jencks, Christopher and David Reisman. 1968. The Academic Revolution. Garden City, NY: Doubleday.

Lazear, Edward. 1999. “Culture and Language,” Journal of Political Economy 107:6 (December 1999): S95-S126.

Manski, Charles and David Wise. 1983. College Choice in America. Cambridge: Harvard University Press.

Patton, Lori D. "Reflecting Back, Looking Forward: Civil Rights and Student Affairs (review)” Journal of College Student Development, Volume 46, Number 1, January/February 2005, pp. 104-108

Provasnik, Stephen, Linda Shafer, and Thomas Snyder. Historically Black Colleges and Universities, 1976 to 2001. National Center for Educational Statistics. NCES 2004-062.

Putnam, Robert. 2000. Bowling Alone: The Collapse and Revival of American Community. Simon and Schuster: New York, 2000.

Roebuck, J. B. and K. S. Murty (1993). Historically Black Colleges and Universities, Praeger Publisher.

Rosenbaum, Paul R. and Donald B. Rubin. "The Central Role of the Propensity Score in Observational Studies for Causal Effects.” Biometrika. Vol 70, 1 (Apr. 1983), 41-55.

Rosenbaum, Paul R. and Donald B. Rubin. "Reducing Bias in Observational Studies Using Subclassification on the Propensity Score.” Journal of the American Statistical Association. Vol 79, 387 (Sept. 1984), 516-524.

Rubin, Donald B. “Assignment to a Treatment Group on the Basis of a Covariate." Journal of

Educational Statistics. Vol. 2, 1 (Spring 1977), 1-26.

Tatum, Beverly D. Why are All the Black Kids Sitting Together in the Cafeteria? And Other 
Conversations about Race. New York: Basic Books, 1997.

US News and World Report. (2006). America's Best Colleges and Universities.

U.S. Dept. of Education, National Center for Education Statistics. HIGHER EDUCATION GENERAL INFORMATION SURVEY (HEGIS) XVI: FINANCIAL STATISTICS OF INSTITUTIONS OF HIGHER EDUCATION FOR FISCAL YEAR 1981 [Computer file]. ICPSR version. Washington, DC: U.S. Dept. of Education, National Center for Education Statistics [producer], 1981. Ann Arbor, MI: Inter-university Consortium for Political and Social Research [distributor], 2005.

U.S. Dept. of Education, National Center for Education Statistics. INTEGRATED POSTSECONDARY EDUCATION DATA SYSTEM (IPEDS): FALL ENROLLMENT ANALYSIS, 1989 [Computer file]. ICPSR Version. Washington, DC: U.S. Dept. of Education, National Center for Education Statistics [producer], 1994. Ann Arbor, MI: Inter-university Consortium for Political and Social Research [distributor], 2003.

Wilson, William J. The Truly Disadvantaged: The Inner City, the Underclass, and Public Policy. 1987. Chicago, IL: University of Chicago Press. 


\section{Appendix: Data Description}

General structure of dummy variables used on right-hand side of regressions

\section{- $\quad$ Family income}

Five dummy variables: family income in 1972 dollars less than $\$ 3,000, \$ 3,000$ to $\$ 5,999, \$ 6,000$ to $\$ 8,999$, greater than or equal to $\$ 9,000$, and missing. We omitted the less than $\$ 3,000$ category.

\section{- Parents' education}

For each parent, four dummy variables: less than bachelor's degree, bachelor's degree, more than bachelor's degree, and missing. We omitted the less than bachelor's degree category.

\section{- $\quad \underline{\text { Test scores }}$}

For combined SAT scores, four dummy variables: less than 600, 600 to 800 , greater than 800 , and missing. For composite ACT scores, four dummy variables: less than 11, 11 to 15, greater than 15, and missing. We omitted the lowest category in each case.

\section{- $\quad$ High school grades}

Four dummy variables: GPA on a four-point scale less than 2.5, from 2.5 to 3.5 , greater than 3.5 , and missing. We omitted the lowest category.

\section{- Binary variables (sex, rural, South, private high school)}

Three dummy variables: each of the binary possibilities, and missing.

- $\quad$ LLS 1972

\section{- $\underline{\text { Race }}$}

The dataset contains numerous race variables collected in different years. In 29 cases, these variables are not mutually consistent. We identified black and white students using the composite race variable in the 1974 data, because this variable is missing in the fewest cases.

\section{- $\underline{\text { Sex }}$}

The dataset contains several sex variables collected in different years. In 22 cases among the students whom we identified as black, these variables are not mutually consistent. We identified students as male or female according to the composite sex variable in the 1974 data.

\section{- $\quad$ HBCU attendance}

We investigated the effect of a student's first college being a historically black institution. In each wave of the survey, students were asked whether they had attended any institution of higher education since the previous wave. If they had, they reported the name of the institution; whether it was a vocational school, a two-year college, or a four-year college; and the first date on which they attended this school. We 
compared the dates of attendance at all four-year colleges reported to find the first four-year college attended, if any. The survey includes a unique numerical code for each college; we used these codes to determine whether the first college was historically black. We restricted our sample to students who reported attending at least one four-year college. We did not use the transcript data in the NLS to determine whether a student went to college and, if so, what college the student attended first because transcripts are sometimes missing.

\section{- Wages and employment status}

We computed hourly wages only for full-time workers, whom we defined as individuals who worked at least 30 hours per week.

Respondents were asked in 1986 to report their salary in their current or most recent job. The wage could be reported in hourly, weekly, bi-weekly, monthly or yearly increments. Respondents also said how many hours they worked per week in this job. For full-time workers who reported a weekly salary, we converted to an hourly wage by dividing the salary by hours worked per week. We divided biweekly salaries by two times the hours worked per week, monthly salaries by $(52 / 12)$ times the hours worked per week, and yearly salaries by 52 times the hours worked per week.

We did not create the wage variable for individuals whose calculated wages were extremely low or high wages. We considered a calculated wage to be too low if it was less than half the federal minimum wage in 1986 (\$3.35). We also rejected as an outlier one individual whose calculated wage was more than $\$ 14,000$ per hour; all other calculated wages were less than $\$ 1,000$ per hour. We converted wages to 1982-1984 dollars by dividing by the 1986 CPI-U.

\section{Family income}

In 1972, students were asked, "What is the approximate income before taxes of your parents (or guardian)? Include taxable and non-taxable from all sources."

\section{- Parents' education}

We used the composite father's education and composite mother's education variables in the 1974 data.

\section{- $\quad \underline{\text { Test scores }}$}

The combined SAT score is the sum of the reported SAT math and verbal scores. The data include the composite ACT score.

\section{- High school grades}

In 1972, students were asked, "Which of the following best describes your grades so far in high school?" The options were: 1) mostly A, 2) about half A and half B, 3) mostly B, and so on up to 7) mostly D, and 8) mostly below D. Call the reported number X. We approximated the student's grade point average on a four-point scale by $(9-\mathrm{X}) / 2$, which works out to 4.0 for students reporting mostly A's, 3.0 for students reporting mostly B's, and so on.

\section{- $\underline{\text { Rural }}$}

The variable is one if the student reported living in a rural or farming community. 


\section{- $\underline{\text { South }}$}

The variable is one if the student's reported region of residence in high school was in the South.

\section{- Private high school}

The variable is one if the student's high school principal or counselor described the school as private or Catholic.

\section{- $\quad$ Post-secondary education}

Respondents were asked, "As of the first week of February 1986, what was your highest level of education?" In addition, the data include transcripts from most post-secondary institutions that respondents attended. We considered a respondent to have a bachelor's degree if the person reported completing college or receiving a master's degree, doctorate or advanced professional degree, or if any of the transcripts showed a bachelor's degree. We considered a person to have received a graduate degree if the person reported receiving a master's degree, doctorate or advanced professional degree, or if any of the transcripts showed such a degree.

To determine whether a person had attended graduate school, we began with the self-reported information on post-secondary attendance that we had used to identify the first college attended. Respondents were asked, "What kind of certificate, license, diploma, or degree were you studying for?" We considered the respondent to have attended graduate school if, at any time, he or she reported studying for a master's degree, a doctorate or an advanced professional degree. In addition, any respondent who never reported studying for a graduate degree, but whose transcripts showed such a degree, was coded as having attended graduate school.

\section{- $\quad$ College majors}

We considered the student's major for the first bachelor's degree received, based on the dates shown on the student's transcripts. The data include 661 six-digit codes for college majors. We categorized any of the 74 codes beginning with 06,07 and 08 as a business major; any of the 53 codes beginning with 11 , 14, 27 and 40 as a major in computer science, mathematics, physical science or engineering; and any of the 108 codes beginning with 17, 18 and 26, plus code 190503, as a major in health or biological science. The categorization was chosen to match as nearly as possible the much less specific categories used in the Baccalaureate and Beyond data. If a student received two bachelor's degrees on the same date, we counted the student as having a major in a particular field if either degree showed a major in that field.

\section{- Utility measures}

In 1986, respondents were asked "how do you feel about" the following statements: "I take a positive attitude toward myself"; "I feel I am a person of worth, on an equal plane with others"; and "I am able to do things as well as most other people." Respondents could say they agreed strongly, agreed, disagreed, disagreed strongly, or had no opinion. We converted these questions to binary variables by coding "agree strongly" and "agree" as a positive response, "disagree" and "disagree strongly" as a negative response, and "no opinion" as missing.

\section{- Weights}


We used the nonresponse-adjusted weight for participants in the 1986 fifth follow-up survey.

- $\quad B \& B 1997$

\section{- Race}

Respondents were asked their race in the 1993 survey; they were then asked to confirm or correct this selection in the 1994 survey. We limited the sample to students who identified themselves as black in the 1994 survey.

- $\underline{\text { Sex }}$

Respondents were asked their gender when it was not obvious to the interviewer.

\section{- $\quad$ HBCU attendance}

We investigated the effect of receiving a bachelor's degree from a HBCU. The data contain a variable indicating whether the student received a bachelor's degree from a HBCU, transferred from a HBCU to the degree institution, or both. The variable is missing either if the student is known never to have attended a HBCU or if there is no information on whether the student ever attended a HBCU. We checked this variable by merging the school codes for bachelor's degree institutions to our list of HBCUs. Among black students, the only discrepancies were in 10 cases where the HBCU variable in the data was missing but our list showed that the school was a HBCU. We used the results from merging the school codes to our list.

\section{- Wages and employment status}

We divided the annual salary recorded for the respondent's April 1997 job by 52 times the average number of hours worked per week. The data define full-time workers as non-teachers who worked at least 30 hours per week and teachers who described themselves as working full time. We rejected as outliers three cases where the calculated hourly wage was less than half the federal minimum wage in 1997 (\$5.15). We found no implausibly high wages. We converted wages to 1982-1984 dollars by dividing by the 1997 CPI-U.

\section{Family income}

We used family income in 1991 and converted to 1972 dollars by dividing by the annual CPI-U. For students who were their parents' dependents in 1991, total family taxed and untaxed income was obtained, in order of priority, from the student's financial aid application, a telephone interview of parents, a telephone interview of the student, the student's Pell grant file, or the student loan file. For students who were not their parents' dependents, the variable is the student's own taxed and untaxed income. This was obtained, in order of priority, from the financial aid application, the student's phone interview, the student's Pell grant file, or the student loan file.

\section{- $\quad$ Parents' education}

The data contain variables from 1994 and 1997 indicating each parent's highest level of education. The only cases in which these variables disagree are where one of them is missing. We combined them. 


\section{- $\quad$ Test scores}

The data list combined SAT scores and composite ACT scores.

\section{- South}

The variable is one if the parents' state of legal residence was Alabama, Arkansas, Delaware, the District of Columbia, Florida, Georgia, Kentucky, Louisiana, Maryland, Mississippi, North Carolina, Oklahoma, South Carolina, Tennessee, Texas, Virginia or West Virginia.

\section{- $\quad$ Private high school}

The variable is one if the student said he or she graduated from a Catholic, other religious, or nonreligious private high school.

\section{- $\quad$ Post-secondary education}

All students in this dataset received a bachelor's degree. The data contains variables listing the highest degree a student reported receiving after the bachelor's and the highest-level degree program in which the student enrolled after receiving the bachelor's. The degrees that can be listed in these variables are: doctorate, first professional, post-master's certificate, MBA, master's, bachelor's, associate's, and other certificate or license. We classify the student as having received a graduate degree or attended a graduate program if the variable lists a doctorate, first professional degree, post-master's certificate, MBA or master's. We verified that all students who received graduate degrees are listed as having attended a graduate program.

\section{- College majors}

The dataset contains a composite variable indicating the student's major that was compiled from student surveys, transcripts and financial aid records. This variable lists 12 broad categories of majors. We record a physical science major if this variable lists the major as engineering or "mathematics and other sciences," which consist of computer science and physical sciences. We record a health and biological science major when the variable indicates a major in either "health professions" or "biological science." We record a business major when the variable indicates "business and management."

\section{- Weights}

We weighted by the nonresponse-adjusted weight for respondents to the 1997 survey.

- College and Beyond

\section{- $\quad \underline{\text { Race }}$}

The institutional data files contain two variables indicating the student's ethnicity. We limited the sample to students listed as black in either of these variables. 
- $\underline{\text { Sex }}$

From the institutional data.

\section{- HBCU attendance}

The four HBCUs in the College and Beyond sample are Howard University, Morehouse College, Spelman College and Xavier University of Louisiana.

\section{- Wages and employment status}

Respondents reported their annual pre-tax earned income, including income from jobs; net income from businesses, farms or rent; pensions; and Social Security. They were instructed not to include income from dividends and interest and not to count the income of other family members. They reported income in 10 categories. We take the midpoint of each bracket except the top bracket, which is $\$ 200,000$ or more. For the top bracket, we follow Dale and Krueger (2002) and use the average income shown in the 1990 census for college graduates in the appropriate cohort who earned more than $\$ 200,000$ per year. We included all individuals with reported income in our regressions.

We also considered full-time employment as an outcome. Respondents were asked, "Are you currently working for pay or profit?" If they answered yes, they were asked whether they were working "only or mostly full-time," "some full-time and some part-time," or "only or mostly part-time." We coded only the first of these categories as full-time employment.

\section{Family income}

We used the family income variable from the HERI student survey; this is a categorical variable. We converted to 1972 dollars using the CPI-U.

\section{- $\quad$ Parents' education}

When a parent's education is listed as "attended or graduated from college (can't tell)", we categorized the parent as having less than a bachelor's degree.

\section{- $\quad \underline{T e s t ~ s c o r e s ~}$}

We used SAT scores from the Educational Testing Service file and ACT scores from the institutional data.

\section{- High school grades}

We obtained high school grades from the HERI student survey. This variable lists the student's average high school grade as either D, C, C+, B-, B, B+, A-, and A or A+. We treat D as a GPA of 1, C as a GPA of $2, \mathrm{C}+$ as a GPA of 2.33, B- as a GPA of 2.67, B as a GPA of 3, B+ as a GPA of 3.33, A- as a GPA of 3.67 , and $\mathrm{A}$ or $\mathrm{A}+$ as a GPA of 4 .

\section{- $\underline{\text { South }}$}

The variable is one if, when he or she applied to college, the student lived in Alabama, Arkansas, Delaware, the District of Columbia, Florida, Georgia, Kentucky, Louisiana, Maryland, Mississippi, North 
Carolina, Oklahoma, South Carolina, Tennessee, Texas, Virginia or West Virginia.

\section{- $\quad$ Private high school}

The variable is one if the student attended a parochial or private high school.

\section{- Post-secondary education}

Respondents were asked in the follow-up survey whether they had received a bachelor's degree. For each of more than 20 kinds of graduate and professional degrees, respondents were asked whether they had studied for the degree and whether they had actually received it. We combined these responses into binary variables indicating whether the respondent studied for or received any graduate degree.

\section{- $\quad$ College majors}

The data list up to two majors for each student. We recorded a major in physical science if either major was engineering, computer and information sciences, mathematics, astronomy/atmospheric sciences, chemistry, geological sciences, physics, or other physical sciences. We recorded a major in health or biological sciences if either major was biological sciences, pre-med, nursing, dentistry, or health sciences. We recorded a major in business if either major was business and management.

In 1989, five major codes - 345, 734, 905, 920 and 980 - appear in the data but not in the codebook. A total of 17 black students have one of these codes. We assumed none of these codes represented a physical science, a health or biological science, or a business field.

\section{- Development as an undergraduate}

Respondents indicated on a one-to-five scale, where five represented "a great deal" and one represented "not at all," how much their undergraduate experiences helped them develop in each of 15 areas. We kept these variables in continuous form.

\section{- Job satisfaction}

Respondents were asked about 13 aspects of job satisfaction. In each category, they could indicate they were "very satisfied," "somewhat satisfied," or "not satisfied." We converted these variables to binary form by coding "very satisfied" as one and "somewhat" or "not satisfied" as zero. We examined each of the 13 binary variables separately. We also computed the first principal component of the 13 binary variables and examined the resulting continuous variable.

\section{- Utility measures}

Respondents were asked:

"In general, how satisfied would you say you are with your life right now?" and

"Overall, how satisfied have you been with the undergraduate education you received at the school at which you first enrolled?"

The possible responses were "very satisfied," "somewhat satisfied," "neither satisfied nor dissatisfied," "somewhat dissatisfied," and "very dissatisfied." We converted these to binary variables by coding "very" and "somewhat satisfied" as one and the remaining categories as zero. 
Respondents were also asked, "Imagine that you had your life to live over again and were graduating from high school. Knowing what you do now, how likely is it that you would choose the same undergraduate school?" Possible responses were "very likely," "somewhat likely," and "not likely. We converted this to a binary variable by coding "very" and "somewhat likely" as one and "not likely" as zero.

\section{$\underline{\text { Academic outcomes index }}$}

The first principal component of the dummy variables for majoring in business, majoring in physical science/mathematics/computer science/engineering, majoring in biological science/health, receiving a bachelor's degree, attending graduate school, and receiving a graduate degree.

\section{Subjective academic index}

The first principal component of the dummy variable for being satisfied with the undergraduate education; the dummy variable for being likely to choose the same undergraduate school again; the dummy variable for reporting that anyone took a special interest in one's work at the undergraduate school; a variable that rates on a one-to-five scale how much the undergraduate education helped develop analytical and problem-solving skills; and a variable that rates on a one-to-five scale how much the undergraduate education helped develop knowledge of a particular field.

\section{Subjective labor market index}

The first principal component of dummy variables for whether the person reported being very satisfied with the following characteristics of the current job: intellectual challenge, flexible schedule, high level of responsibility, low stress, working environment, job security, employer-supported child care, fair treatment of women and minorities, high income, good benefits, promotion opportunities, and service to society.

\section{Leadership/lifestyle index}

The first principal component of variables rating, on a one-to-five scale, how much the undergraduate education helped develop each of the following: leadership abilities, interest in community service, religious values, ability to communicate orally, competitiveness, ability to work cooperatively, ability to relax or enjoy leisure, ability to write clearly and effectively, and ability to adapt to change.

\section{$\underline{\text { Social interactions index }}$}

The first principal component of variables rating, on a one-to-five scale, how much the undergraduate education helped develop each of the following: ability to form and retain friendships, ability to have rapport with people of different beliefs, and ability to work and get along with people of different races.

\section{- $\quad$ Other outcome variables}

The other outcome variables we studied are binary in the data.

\section{- Weights}

Because the College and Beyond surveys included $100 \%$ of minority students at the sample schools, there is no need to use weights. 
Table 1: Summary Statistics of Black Students Data Files

\begin{tabular}{|c|c|c|c|c|c|c|c|c|c|c|}
\hline \multirow[t]{2}{*}{ definition of $\mathrm{HBCU}$} & \multicolumn{2}{|c|}{$\begin{array}{l}\text { NLS (1972) } \\
\text { first college }\end{array}$} & \multicolumn{2}{|c|}{$\begin{array}{c}\text { NLS (1972) } \\
\text { bachelor's degree college }\end{array}$} & \multicolumn{2}{|c|}{$\begin{array}{c}\text { B\&B (1997) } \\
\text { bachelor's degree college }\end{array}$} & \multicolumn{2}{|c|}{$\begin{array}{l}\text { C\&B (1976) } \\
\text { first college }\end{array}$} & \multicolumn{2}{|c|}{$\begin{array}{l}\text { C\&B (1989) } \\
\text { first college }\end{array}$} \\
\hline & $\mathrm{HBCU}$ & TWI & HBCU & TWI & $\mathrm{HBCU}$ & TWI & $\mathrm{HBCU}$ & TWI & $\mathrm{HBCU}$ & TWI \\
\hline \multicolumn{11}{|l|}{ Pre-College Academic Background } \\
\hline SAT combined & $661.77(114.84)$ & 788.85 (172.68) & 677.78 (120.23) & $805.60(198.57)$ & 768.62 (197.61) & $832.14(183.37)$ & $795.50(161.29)$ & $973.11(171.39)$ & 891.58 (154.94) & $1043.18(164.37)$ \\
\hline ACT composite & $12.60(4.09)$ & $15.13(4.80)$ & $13.43(4.90)$ & $15.93(4.84)$ & $16.52(4.37)$ & $18.87(5.39)$ & $12.64(4.21)$ & $21.17(4.74)$ & $18.73(4.55)$ & $22.30(3.72)$ \\
\hline high school GPA & $2.86(0.58)$ & $2.83(0.65)$ & $2.98(0.55)$ & $2.88(0.64)$ & & & $3.03(0.51)$ & $3.40(0.44)$ & $3.15(0.54)$ & $3.42(0.41)$ \\
\hline private high school & 0.158 & 0.073 & 0.238 & 0.082 & 0.062 & 0.207 & 0.214 & 0.312 & 0.248 & 0.300 \\
\hline \multicolumn{11}{|l|}{ Pre-College Personal and Family Background } \\
\hline female & 0.707 & 0.630 & 0.737 & 0.587 & 0.721 & 0.639 & 0.566 & 0.602 & 0.390 & 0.615 \\
\hline family income (1972 \$): <\$3000 & 0.198 & 0.233 & 0.187 & 0.116 & 0.256 & 0.236 & 0.132 & 0.086 & 0.098 & 0.071 \\
\hline family income (1972 \$): \$3000-\$5999 & 0.215 & 0.183 & 0.221 & 0.159 & 0.174 & 0.133 & 0.182 & 0.149 & 0.148 & 0.101 \\
\hline family income (1972 \$): \$6000-\$8999 & 0.325 & 0.261 & 0.376 & 0.339 & 0.185 & 0.146 & 0.202 & 0.230 & 0.082 & 0.092 \\
\hline family income (1972 \$): >=\$9000 & 0.262 & 0.323 & 0.215 & 0.386 & 0.385 & 0.485 & 0.484 & 0.535 & 0.672 & 0.735 \\
\hline father's education < bachelor's & 0.950 & 0.867 & 0.972 & 0.793 & 0.572 & 0.742 & 0.708 & 0.606 & 0.443 & 0.565 \\
\hline father's education = bachelor's & 0.033 & 0.080 & 0.026 & 0.140 & 0.247 & 0.141 & 0.197 & 0.265 & 0.317 & 0.240 \\
\hline father's education > bachelor's & 0.017 & 0.053 & 0.002 & 0.067 & 0.181 & 0.117 & 0.095 & 0.129 & 0.240 & 0.194 \\
\hline mother's education < bachelor's & 0.925 & 0.914 & 0.939 & 0.886 & 0.573 & 0.740 & 0.670 & 0.611 & 0.376 & 0.554 \\
\hline mother's education = bachelor's & 0.038 & 0.052 & 0.045 & 0.067 & 0.192 & 0.134 & 0.234 & 0.273 & 0.333 & 0.298 \\
\hline mother's education > bachelor's & 0.037 & 0.034 & 0.016 & 0.047 & 0.235 & 0.126 & 0.096 & 0.116 & 0.290 & 0.149 \\
\hline south & 0.866 & 0.389 & 0.873 & 0.340 & 0.709 & 0.494 & 0.622 & 0.236 & 0.676 & 0.237 \\
\hline rural & 0.162 & 0.089 & 0.167 & 0.078 & - & - & - & - & - & \\
\hline \multicolumn{11}{|l|}{ Post-High School Outcomes } \\
\hline income & $12.82(35.70)$ & $10.55(8.59)$ & $14.46(45.52)$ & $11.38(7.70)$ & $7.68(3.06)$ & $9.12(3.88)$ & 33145 (26288) & $39768(32222)$ & 16247 (11460) & $18634(17450)$ \\
\hline In (income) & $2.16(0.61)$ & $2.21(0.52)$ & $2.20(0.62)$ & $2.32(0.46)$ & $1.97(0.37)$ & $2.14(0.38)$ & $10.11(0.93)$ & $10.26(1.01)$ & $9.28(1.20)$ & $9.42(1.17)$ \\
\hline physical science major & 0.074 & 0.025 & 0.051 & 0.040 & 0.139 & 0.083 & 0.147 & 0.127 & 0.268 & 0.146 \\
\hline biological science major & 0.075 & 0.103 & 0.077 & 0.101 & 0.075 & 0.146 & 0.212 & 0.144 & 0.284 & 0.107 \\
\hline business major & 0.183 & 0.333 & 0.191 & 0.324 & 0.317 & 0.245 & 0.185 & 0.078 & 0.263 & 0.085 \\
\hline attended graduate school & 0.321 & 0.197 & 0.492 & 0.347 & 0.361 & 0.299 & 0.538 & 0.648 & 0.482 & 0.522 \\
\hline received graduate degree & 0.104 & 0.128 & 0.183 & 0.220 & 0.096 & 0.097 & 0.314 & 0.482 & 0.404 & 0.440 \\
\hline received bachelor's degree & 0.648 & 0.560 & 1.000 & 1.000 & 1.000 & 1.000 & 0.782 & 0.896 & 0.815 & 0.913 \\
\hline treated unfairly in job because of race & 0.211 & 0.212 & 0.214 & 0.159 & - & - & - & & & \\
\hline employed full time & 0.823 & 0.946 & 0.762 & 0.937 & 0.914 & 0.954 & 0.571 & 0.669 & 0.580 & 0.574 \\
\hline satisfied with life & 0.735 & 0.815 & 0.660 & 0.924 & - & - & 0.829 & 0.829 & 0.810 & 0.791 \\
\hline would choose same college again & - & - & - & - & - & - & 0.670 & 0.543 & 0.653 & 0.657 \\
\hline college developed ability to get along with other races ( $1-5$ scale) & - & - & - & - & - & - & $3.608(1.262)$ & $3.561(1.288)$ & $3.468(1.372)$ & $3.947(1.197)$ \\
\hline fraction black in zip code & - & - & - & - & - & - & 0.597 & 0.565 & 0.532 & 0.345 \\
\hline participates in political activities & - & - & - & - & - & - & 0.335 & 0.317 & 0.634 & 0.465 \\
\hline participates in religious activities & - & - & - & - & - & - & 0.641 & 0.561 & 0.727 & 0.605 \\
\hline participates in civil rights activities & - & - & - & - & - & - & 0.533 & 0.529 & 0.711 & 0.614 \\
\hline $\begin{array}{l}\text { participates in social service activities } \\
\text { nate }\end{array}$ & - & - & - & - & - & - & 0.255 & 0.299 & 0.613 & 0.500 \\
\hline participates in alumni activities & - & - & - & - & - & - & 0.372 & 0.374 & 0.668 & 0.579 \\
\hline \multicolumn{11}{|l|}{ Sample Size Details } \\
\hline$\overline{\text { Observations }}$ & 260 & 364 & 164 & 224 & 172 & 415 & 983 & 1142 & 623 & 1162 \\
\hline Number with Missing Values for at least 1 Variable & 259 & 360 & 164 & 219 & 172 & 415 & 983 & 1142 & 623 & 1162 \\
\hline Number with Missing Values for Wages & 57 & 71 & 32 & 48 & 48 & 113 & 20 & 123 & 12 & 14 \\
\hline
\end{tabular}

Notes: The entries report the means of variables listed in the row headings. For SAT combined,

parentheses. The NLS and BB income variables are hourly wages reported in 1986 and 1997, respectively. The C\&B income variables are annual income reported in 1995 for the 1976 sample, and in 1996 for the 1989 sample. The

perse 
Table 2: Determinants of HBCU Attendance Among Blacks in NLS and BB

\begin{tabular}{|c|c|c|c|}
\hline $\begin{array}{l}\text { Dataset } \\
\text { HBCU Definition }\end{array}$ & $\begin{array}{l}\text { NLS (1972) } \\
\text { first college } \\
\text { (1) }\end{array}$ & $\begin{array}{c}\text { NLS (1972) } \\
\text { bachelor's degree college } \\
(2)\end{array}$ & $\begin{array}{c}\mathrm{BB}(1997) \\
\text { bachelor's degree college } \\
(3)\end{array}$ \\
\hline SAT: $600-800$ & $\begin{array}{l}-0.170 \\
(0.072)\end{array}$ & $\begin{array}{l}-0.012 \\
(0.112)\end{array}$ & $\begin{array}{l}-0.032 \\
(0.128)\end{array}$ \\
\hline SAT: $>800$ & $\begin{array}{l}-0.320 \\
(0.049)\end{array}$ & $\begin{array}{l}-0.226 \\
(0.081)\end{array}$ & $\begin{array}{l}-0.067 \\
(0.120)\end{array}$ \\
\hline ACT: 11-15 & $\begin{array}{l}-0.116 \\
(0.112)\end{array}$ & $\begin{array}{l}-0.306 \\
(0.058)\end{array}$ & $\begin{array}{c}0.130 \\
(0.200)\end{array}$ \\
\hline ACT: $>15$ & $\begin{array}{l}-0.213 \\
(0.083)\end{array}$ & $\begin{array}{l}-0.296 \\
(0.062)\end{array}$ & $\begin{array}{l}-0.167 \\
(0.109)\end{array}$ \\
\hline family income: $\$ 3000-\$ 5999$ & $\begin{array}{c}0.018 \\
(0.079)\end{array}$ & $\begin{array}{c}0.010 \\
(0.117)\end{array}$ & $\begin{array}{c}0.064 \\
(0.089)\end{array}$ \\
\hline family income: $\$ 6000-\$ 8999$ & $\begin{array}{l}-0.069 \\
(0.077)\end{array}$ & $\begin{array}{l}-0.174 \\
(0.092)\end{array}$ & $\begin{array}{c}0.073 \\
(0.099)\end{array}$ \\
\hline family income: $>=\$ 9000$ & $\begin{array}{c}0.062 \\
(0.088)\end{array}$ & $\begin{array}{l}-0.014 \\
(0.113)\end{array}$ & $\begin{array}{l}-0.058 \\
(0.063)\end{array}$ \\
\hline father's education: bachelor's & $\begin{array}{l}-0.031 \\
(0.144)\end{array}$ & $\begin{array}{l}-0.154 \\
(0.130)\end{array}$ & $\begin{array}{c}0.165 \\
(0.087)\end{array}$ \\
\hline father's education: >bachelor's & $\begin{array}{l}-0.130 \\
(0.112)\end{array}$ & $\begin{array}{l}-0.318 \\
(0.036)\end{array}$ & $\begin{array}{c}0.127 \\
(0.110)\end{array}$ \\
\hline mother's education: bachelor's & $\begin{array}{c}0.097 \\
(0.145)\end{array}$ & $\begin{array}{c}0.230 \\
(0.182)\end{array}$ & $\begin{array}{c}0.144 \\
(0.086)\end{array}$ \\
\hline mother's education: >bachelor's & $\begin{array}{c}0.082 \\
(0.133)\end{array}$ & $\begin{array}{c}0.035 \\
(0.156)\end{array}$ & $\begin{array}{c}0.280 \\
(0.115)\end{array}$ \\
\hline south & $\begin{array}{c}0.429 \\
(0.049)\end{array}$ & $\begin{array}{c}0.473 \\
(0.060)\end{array}$ & $\begin{array}{l}0.126 \\
(0.054)\end{array}$ \\
\hline private high school & $\begin{array}{l}-0.065 \\
(0.132)\end{array}$ & $\begin{array}{c}0.099 \\
(0.153)\end{array}$ & $\begin{array}{l}-0.139 \\
(0.059)\end{array}$ \\
\hline female & $\begin{array}{c}0.033 \\
(0.053)\end{array}$ & $\begin{array}{c}0.024 \\
(0.069)\end{array}$ & $\begin{array}{c}0.047 \\
(0.057)\end{array}$ \\
\hline $\begin{array}{l}\text { Observations } \\
\text { pseudo R-squared }\end{array}$ & $\begin{array}{l}496 \\
0.24\end{array}$ & $\begin{array}{l}308 \\
0.31\end{array}$ & $\begin{array}{l}424 \\
0.15\end{array}$ \\
\hline
\end{tabular}

Notes: The tables reports the results from the estimation of probits for the probability of enrolling at a HBCU (column 1) and graduating from a HBCU (columns 2 and 3 ). All of the explanatory variables (noted in the row headings are indicators, so the entries report the discrete change in the probability associated with a change in value from zero to one and the associated heteroskedastic-consistent standard error. (The standard errors in the columns (1) and (2) are clustered by high school.) The omitted categories are: SAT $<600, A C T<11$, family income $<\$ 3000$, father's education $<$ bachelor's, mother's education < bachelor's. The models also include dummy variables for each category whose value is one when the categorical variable is missing. The samples are limited to Blacks with measured 1986 wages (NLS) or measured 1997 wages (B\&B). In the B\&B, 2 observations were dropped because a regressor perfectly predicted the outcome. See the text for further details. 


\begin{tabular}{|c|c|c|c|c|c|c|}
\hline & $\begin{array}{l}\text { Linear Regression } \\
\text { without Controls } \\
\text { (1) }\end{array}$ & $\begin{array}{c}\text { Linear Regression } \\
\text { with Controls } \\
(2)\end{array}$ & $\begin{array}{c}\text { Propensity Score } \\
\text { Kernel Matching } \\
\text { (3) }\end{array}$ & $\begin{array}{c}\text { Propensity Score } \\
\text { Radius Matching } \\
\text { (4) }\end{array}$ & $\begin{array}{l}\text { Selection correction } \\
\text { for Missing Wages } \\
\text { (5) }\end{array}$ & $\begin{array}{c}\text { Dale-Krueger } \\
\text { with controls } \\
(6)\end{array}$ \\
\hline \multicolumn{7}{|c|}{ A. National Longitudinal Survey: log(1986 hourly wage); treatment: first college was HBCU } \\
\hline HBCU coefficient & $\begin{array}{l}-0.051 \\
(0.078)\end{array}$ & $\begin{array}{c}0.111 \\
(0.066)\end{array}$ & $\begin{array}{c}0.129 \\
(0.065)\end{array}$ & $\begin{array}{c}0.134 \\
(0.066)\end{array}$ & $\begin{array}{c}0.123 \\
(0.103)\end{array}$ & $\begin{array}{l}.225 \\
(.094)\end{array}$ \\
\hline R-squared & 0.002 & 0.154 & & & & \\
\hline Number HBCU & 203 & 203 & 203 & 203 & 260 & 98 \\
\hline Number TWI & 293 & 293 & 286 & 286 & 364 & 151 \\
\hline \multicolumn{7}{|c|}{ B. National Longitudinal Survey: log(1986 hourly wage); treatment: bachelor's degree from HBCU } \\
\hline HBCU coefficient & $\begin{array}{l}-0.115 \\
(0.090)\end{array}$ & $\begin{array}{c}0.060 \\
(0.083)\end{array}$ & $\begin{array}{c}0.055 \\
(0.085)\end{array}$ & $\begin{array}{c}0.062 \\
(0.073)\end{array}$ & $\begin{array}{c}0.111 \\
(0.071)\end{array}$ & - \\
\hline R-squared & 0.011 & 0.150 & & & & \\
\hline Number HBCU & 132 & 132 & 132 & 132 & 164 & - \\
\hline Number TWI & 176 & 176 & 155 & 155 & 224 & - \\
\hline \multicolumn{7}{|c|}{ C. Baccalaureate and Beyond: log(1997 hourly wage); treatment: bachelor's degree from HBCU } \\
\hline HBCU coefficient & $\begin{array}{l}-0.166 \\
(0.051)\end{array}$ & $\begin{array}{l}-0.138 \\
(0.050)\end{array}$ & $\begin{array}{l}-0.144 \\
(0.044)\end{array}$ & $\begin{array}{l}-0.142 \\
(0.041)\end{array}$ & $\begin{array}{l}-0.121 \\
(0.043)\end{array}$ & - \\
\hline R-squared & 0.037 & 0.107 & & & & \\
\hline Number HBCU & 124 & 124 & 124 & 124 & 172 & - \\
\hline Number TWI & 300 & 300 & 278 & 278 & 415 & - \\
\hline
\end{tabular}

Notes: The entries in columns (1), (2), (5), and (6) are from least squares regression. In all cases, the coefficient associated with the $\mathrm{HBCU}$ indicator is reported, along with its standard error. The variance-covariance matrix allows for unspecifed heteroskedasticity in these columns and in the NLS samples we allow for clustering at the high school level. These equations are weighted by the NLS and B\&B sampling weights, respectively. The column (1) estimate is not adjusted for any covariates, while column (2) adds the full set of independent variables used in the probit in Table 2. Column (5) includes the inverse Mill's ratio that is derived from the estimation of an equation for missing wages, as well as the column (2) controls. These standard errors fail to account for heteroskedasticity or

clustering. Column (6) adds indicators based on quartiles of the median SAT score at the school with the highest SAT score among the schools where the student was admitted. All observations with missing or zero wages are dropped.

Columns (3) and (4) report on the propensity score matching results. The former uses a gaussian kernel with a bandwidth of 0.1 , while the latter uses radius matching with a bandwidth of 0.1 and with replacement. The STATA code is available at available at http://www.Irz-muenchen.de/ sobecker/pscore.html. Standard errors for matching estimates are computed by bootstrapping, with propensity scores recomputed for each bootstrap sample. The matching estimates are unweighted. Observations are dropped if wages are missing or zero or propensity score is not strictly between 0 and 1 . See the text for more details. 
Table 4: Effects of HBCU Attendance on Non-Wage Outcomes in NLS and BB

\begin{tabular}{|c|c|c|c|}
\hline $\begin{array}{l}\text { Dataset } \\
\text { HBCU Definition }\end{array}$ & $\begin{array}{l}\text { NLS (1972) } \\
\text { first college } \\
\text { (1) }\end{array}$ & $\begin{array}{c}\text { NLS (1972) } \\
\text { bachelor's degree college } \\
\text { (2) }\end{array}$ & $\begin{array}{c}\text { BB (1997) } \\
\text { bachelor's degree college } \\
\text { (3) }\end{array}$ \\
\hline \multicolumn{4}{|l|}{ Employment } \\
\hline employed full time & $\begin{array}{l}-0.018 \\
(0.021)\end{array}$ & $\begin{array}{c}0.045 \\
(0.040)\end{array}$ & $\begin{array}{l}-0.023 \\
(0.025)\end{array}$ \\
\hline \multicolumn{4}{|l|}{ Life Satisfaction } \\
\hline satisfied with life & $\begin{array}{l}-0.004 \\
(0.038)\end{array}$ & $\begin{array}{l}-0.078 \\
(0.049)\end{array}$ & $\begin{array}{l}- \\
-\end{array}$ \\
\hline $\begin{array}{l}\text { treated unfairly in job } \\
\text { because of race }\end{array}$ & $\begin{array}{l}-0.027 \\
(0.046)\end{array}$ & $\begin{array}{c}0.041 \\
(0.055)\end{array}$ & $\begin{array}{l}- \\
-\end{array}$ \\
\hline \multicolumn{4}{|l|}{ Academic Outcomes } \\
\hline received bachelor's degree & $\begin{array}{c}0.098 \\
(0.049)\end{array}$ & $\begin{array}{l}- \\
-\end{array}$ & - \\
\hline attended graduate school & $\begin{array}{c}0.033 \\
(0.042)\end{array}$ & $\begin{array}{c}0.025 \\
(0.061)\end{array}$ & $\begin{array}{c}0.087 \\
(0.041)\end{array}$ \\
\hline received graduate degree & $\begin{array}{c}0.016 \\
(0.030)\end{array}$ & $\begin{array}{c}0.063 \\
(0.049)\end{array}$ & $\begin{array}{c}0.016 \\
(0.036)\end{array}$ \\
\hline physical science major & $\begin{array}{c}0.056 \\
(0.034)\end{array}$ & $\begin{array}{c}0.035 \\
(0.028)\end{array}$ & $\begin{array}{c}0.072 \\
(0.029)\end{array}$ \\
\hline biological science major & $\begin{array}{l}-0.003 \\
(0.047)\end{array}$ & $\begin{array}{c}0.050 \\
(0.032)\end{array}$ & $\begin{array}{l}-0.036 \\
(0.033)\end{array}$ \\
\hline business major & $\begin{array}{c}0.024 \\
(0.075)\end{array}$ & $\begin{array}{c}0.026 \\
(0.073)\end{array}$ & $\begin{array}{l}-0.001 \\
(0.038)\end{array}$ \\
\hline
\end{tabular}

Notes: The entries report the results from propensity score matching routines. The row headings report the

dependent variables. The samples and treatment are noted in the column headings. The entries report the impact of HBCU matriculation (graduation), relative to TWI matriculation (graduation). The propensity score is estimated with a probit and all of the covariates used in Table 2 are included as explanatory variables. The matching method uses a gaussian kernel with a bandwidth of 0.1. The standard errors (reported in parentheses) are computed by bootstrapping, with propensity scores recomputed for each bootstrap sample. The estimates are unweighted. For each outcome, all observations with data on that outcome are used. Observations are dropped if the propensity score is not strictly between 0 and 1 . See the text and notes to Table 3 for more details. 
Table 5: Determinants of HBCU Attendance Among Blacks in C\&B

\begin{tabular}{|c|c|c|c|}
\hline $\begin{array}{l}\text { Dataset } \\
\text { HBCU Definition } \\
\text { Include Howard, Spelman? }\end{array}$ & $\begin{array}{c}\text { C\&B (1976) } \\
\text { first college } \\
\text { yes } \\
(1)\end{array}$ & $\begin{array}{c}\text { C\&B (1976) } \\
\text { first college } \\
\text { no } \\
(2)\end{array}$ & $\begin{array}{c}\text { C\&B (1989) } \\
\text { first college } \\
\text { no } \\
\text { (3) }\end{array}$ \\
\hline SAT: $600-800$ & $\begin{array}{l}-0.212 \\
(0.074)\end{array}$ & $\begin{array}{l}-0.138 \\
(0.035)\end{array}$ & $\begin{array}{l}-0.620 \\
(0.021)\end{array}$ \\
\hline SAT: $>800$ & $\begin{array}{l}-0.584 \\
(0.056)\end{array}$ & $\begin{array}{l}-0.512 \\
(0.075)\end{array}$ & $\begin{array}{l}-0.998 \\
(0.001)\end{array}$ \\
\hline ACT: 11-15 & $\begin{array}{l}-0.315 \\
(0.124)\end{array}$ & $\begin{array}{l}-0.099 \\
(0.052)\end{array}$ & $\begin{array}{l}-0.124 \\
(0.180)\end{array}$ \\
\hline ACT: $>15$ & $\begin{array}{l}-0.489 \\
(0.039)\end{array}$ & $\begin{array}{l}-0.167 \\
(0.025)\end{array}$ & $\begin{array}{l}-0.336 \\
(0.108)\end{array}$ \\
\hline family income: $\$ 3000-\$ 5999$ & $\begin{array}{c}0.005 \\
(0.067)\end{array}$ & $\begin{array}{l}-0.013 \\
(0.056)\end{array}$ & $\begin{array}{l}-0.089 \\
(0.106)\end{array}$ \\
\hline family income: $\$ 6000-\$ 8999$ & $\begin{array}{l}-0.059 \\
(0.064)\end{array}$ & $\begin{array}{l}-0.091 \\
(0.035)\end{array}$ & $\begin{array}{l}-0.264 \\
(0.068)\end{array}$ \\
\hline family income: $>=\$ 9000$ & $\begin{array}{l}-0.033 \\
(0.060)\end{array}$ & $\begin{array}{l}-0.105 \\
(0.042)\end{array}$ & $\begin{array}{l}-0.271 \\
(0.073)\end{array}$ \\
\hline father's education: bachelor's & $\begin{array}{l}-0.064 \\
(0.053)\end{array}$ & $\begin{array}{c}0.152 \\
(0.062)\end{array}$ & $\begin{array}{c}0.011 \\
(0.063)\end{array}$ \\
\hline father's education: >bachelor's & $\begin{array}{l}-0.042 \\
(0.068)\end{array}$ & $\begin{array}{l}-0.085 \\
(0.046)\end{array}$ & $\begin{array}{l}-0.065 \\
(0.070)\end{array}$ \\
\hline mother's education: bachelor's & $\begin{array}{c}0.034 \\
(0.052)\end{array}$ & $\begin{array}{c}0.097 \\
(0.055)\end{array}$ & $\begin{array}{c}0.144 \\
(0.068)\end{array}$ \\
\hline mother's education: >bachelor's & $\begin{array}{c}0.101 \\
(0.068)\end{array}$ & $\begin{array}{l}-0.113 \\
(0.039)\end{array}$ & $\begin{array}{c}0.316 \\
(0.070)\end{array}$ \\
\hline south & $\begin{array}{l}0.350 \\
(0.027)\end{array}$ & $\begin{array}{c}0.357 \\
(0.035)\end{array}$ & $\begin{array}{c}0.327 \\
(0.034)\end{array}$ \\
\hline private high school & $\begin{array}{l}-0.051 \\
(0.032)\end{array}$ & $\begin{array}{c}0.093 \\
(0.033)\end{array}$ & $\begin{array}{l}-0.031 \\
(0.039)\end{array}$ \\
\hline female & $\begin{array}{l}-0.077 \\
(0.028)\end{array}$ & $\begin{array}{l}-0.337 \\
(0.034)\end{array}$ & $\begin{array}{l}-0.343 \\
(0.034)\end{array}$ \\
\hline $\begin{array}{l}\text { Observations } \\
\text { pseudo R-squared }\end{array}$ & $\begin{array}{l}1982 \\
0.33\end{array}$ & $\begin{array}{l}1152 \\
0.55\end{array}$ & $\begin{array}{l}1414 \\
0.48\end{array}$ \\
\hline
\end{tabular}

Notes: The tables reports the results from the estimation of probits for the probability of enrolling at a HBCU among the C\&B 1976 (columns 1 and 2) and C\&B 1989 (column 3) samples of Blacks. All of the explanatory variables (noted in the row headings) are indicators, so the entries report the discrete change in the probability associated with a change in value from zero to one and the associated heteroskedastic-consistent standard error. The omitted categories are: SAT $<600, A C T<11$, family income $<\$ 3000$, father's education < bachelor's, mother's education < bachelor's. The models also include dummy variables for each category whose value is one when the categorical variable is missing. The samples are limited to individuals with measured 1995 annual income (C\&B 1976) or measured 1996 annual income (C\&B 1989). In the C\&B 1976 sample without Howard and Spelman colleges, 202 observations were dropped because the regressors perfectly predicted the outcome. In C\&B 1989, 345 observations were dropped because the regressors perfectly predicted the outcome. See the text for further details. 
Table 6: Effects of HBCU Attendance on Labor Market and Other Outcomes in C\&B

\begin{tabular}{|c|c|c|c|}
\hline $\begin{array}{l}\text { Dataset } \\
\text { HBCU Definition } \\
\text { Include Howard, Spelman? }\end{array}$ & $\begin{array}{c}\text { C\&B (1976) } \\
\text { first college } \\
\text { yes } \\
(1)\end{array}$ & $\begin{array}{c}\text { C\&B (1976) } \\
\text { first college } \\
\text { no } \\
(2)\end{array}$ & $\begin{array}{c}\text { C\&B (1989) } \\
\text { first college } \\
\text { no } \\
\text { (3) }\end{array}$ \\
\hline \multicolumn{4}{|l|}{ Labor Market Outcomes } \\
\hline Ln (Annual Income) & $\begin{array}{c}-0.074 \\
(0.069) \\
963 / 1019\end{array}$ & $\begin{array}{l}-0.032 \\
(0.145) \\
335 / 468\end{array}$ & $\begin{array}{l}-0.114 \\
(0.160) \\
611 / 711\end{array}$ \\
\hline employed full time & $\begin{array}{c}0.099 \\
(0.112) \\
110 / 123\end{array}$ & $\begin{array}{c}0.513 \\
(0.363) \\
24 / 10\end{array}$ & $\begin{array}{c}-0.181 \\
(0.202) \\
100 / 109\end{array}$ \\
\hline subjective labor market index & $\begin{array}{c}0.059 \\
(0.061) \\
972 / 1135\end{array}$ & $\begin{array}{c}0.104 \\
(0.164) \\
339 / 532\end{array}$ & $\begin{array}{c}0.032 \\
(0.123) \\
550 / 655\end{array}$ \\
\hline \multicolumn{4}{|l|}{ Life Satisfaction } \\
\hline satisfied with life & $\begin{array}{c}-0.009 \\
(0.026) \\
977 / 1137\end{array}$ & $\begin{array}{l}-0.046 \\
(0.044) \\
341 / 536\end{array}$ & $\begin{array}{l}-0.013 \\
(0.044) \\
621 / 716\end{array}$ \\
\hline college was first choice & $\begin{array}{c}-0.084 \\
(0.034) \\
932 / 1108\end{array}$ & $\begin{array}{l}-0.079 \\
(0.079) \\
314 / 545\end{array}$ & $\begin{array}{l}-0.063 \\
(0.058) \\
613 / 712\end{array}$ \\
\hline $\begin{array}{l}\text { would choose same college } \\
\text { again }\end{array}$ & $\begin{array}{c}0.177 \\
(0.035) \\
981 / 1132\end{array}$ & $\begin{array}{c}0.219 \\
(0.086) \\
340 / 534\end{array}$ & $\begin{array}{l}-0.048 \\
(0.054) \\
622 / 717\end{array}$ \\
\hline leadership/lifestyle index & $\begin{array}{c}0.417 \\
(0.069) \\
977 / 1132\end{array}$ & $\begin{array}{c}0.633 \\
(0.157) \\
341 / 530\end{array}$ & $\begin{array}{c}0.152 \\
(0.109) \\
618 / 717\end{array}$ \\
\hline social interactions index & $\begin{array}{c}0.220 \\
(0.071) \\
976 / 1131\end{array}$ & $\begin{array}{c}0.357 \\
(0.169) \\
341 / 530\end{array}$ & $\begin{array}{c}-0.177 \\
(0.123) \\
619 / 715\end{array}$ \\
\hline $\begin{array}{l}\text { college developed ability to } \\
\text { form and retain friendships }\end{array}$ & $\begin{array}{c}0.423 \\
(0.088) \\
966 / 1100\end{array}$ & $\begin{array}{c}0.530 \\
(0.142) \\
337 / 520\end{array}$ & $\begin{array}{c}0.129 \\
(0.124) \\
613 / 710\end{array}$ \\
\hline $\begin{array}{l}\text { college developed ability to } \\
\text { have rapport w/ people of different beliefs }\end{array}$ & $\begin{array}{c}0.254 \\
(0.088) \\
966 / 1121\end{array}$ & $\begin{array}{c}0.386 \\
(0.205) \\
337 / 526\end{array}$ & $\begin{array}{c}-0.220 \\
(0.116) \\
614 / 709\end{array}$ \\
\hline $\begin{array}{l}\text { college developed ability to } \\
\text { get along with other races }\end{array}$ & $\begin{array}{c}0.034 \\
(0.093) \\
961 / 1124\end{array}$ & $\begin{array}{c}0.255 \\
(0.211) \\
334 / 525\end{array}$ & $\begin{array}{c}-0.445 \\
(0.170) \\
613 / 713\end{array}$ \\
\hline Academic Outcomes & & & \\
\hline$\overline{\text { received bachelor's degree }}$ & $\begin{array}{c}-0.105 \\
(0.025) \\
978 / 1138\end{array}$ & $\begin{array}{c}-0.047 \\
(0.068) \\
339 / 539\end{array}$ & $\begin{array}{c}-0.105 \\
(0.037) \\
623 / 718\end{array}$ \\
\hline attended graduate school & $\begin{array}{c}-0.101 \\
(0.033) \\
983 / 1142\end{array}$ & $\begin{array}{c}-0.116 \\
(0.086) \\
342 / 537\end{array}$ & $\begin{array}{c}-0.019 \\
(0.059) \\
623 / 718\end{array}$ \\
\hline received graduate degree & $\begin{array}{c}-0.136 \\
(0.033) \\
983 / 1142\end{array}$ & $\begin{array}{c}-0.149 \\
(0.082) \\
342 / 537\end{array}$ & $\begin{array}{c}-0.007 \\
(0.057) \\
623 / 718\end{array}$ \\
\hline academic outcomes index & $\begin{array}{c}-0.301 \\
(0.066) \\
983 / 1142\end{array}$ & $\begin{array}{c}-0.296 \\
(0.185) \\
342 / 537\end{array}$ & $\begin{array}{c}-0.123 \\
(0.110) \\
623 / 718\end{array}$ \\
\hline subjective academic index & $\begin{array}{l}0.165 \\
(0.072) \\
082 / 1138\end{array}$ & $\begin{array}{l}0.356 \\
(0.204)\end{array}$ & -0.201 \\
\hline physical science major & $\begin{array}{c}-0.027 \\
(0.028) \\
784 / 771\end{array}$ & $\begin{array}{c}-0.107 \\
(0.080) \\
269 / 459\end{array}$ & $\begin{array}{c}0.074 \\
(0.042) \\
552 / 636\end{array}$ \\
\hline biological science major & 0.087 & 0.120 & 0.196 \\
\hline
\end{tabular}




\begin{tabular}{lccc} 
& $(0.026)$ & $(0.051)$ & $(0.040)$ \\
business major & $784 / 771$ & $269 / 459$ & $552 / 636$ \\
& 0.111 & 0.234 & 0.214 \\
& $(0.021)$ & $(0.030)$ & $(0.028)$ \\
Other & $784 / 771$ & $269 / 459$ & $552 / 636$ \\
fraction black in zip code & & \\
& 0.022 & 0.081 & 0.156 \\
Participation & $(0.025)$ & $(0.074)$ & $(0.041)$ \\
political & $902 / 669$ & $315 / 350$ & $602 / 593$ \\
& & & \\
religious & 0.019 & -0.032 & 0.216 \\
& $(0.032)$ & $(0.078)$ & $(0.065)$ \\
civil rights & $983 / 1142$ & $342 / 537$ & $623 / 718$ \\
& 0.039 & 0.085 & 0.108 \\
& $(0.036)$ & $(0.087)$ & $(0.062)$ \\
social service & $983 / 1142$ & $342 / 537$ & $623 / 718$ \\
& 0.004 & 0.071 & 0.105 \\
alumni & $(0.035)$ & $(0.081)$ & $(0.063)$ \\
& $983 / 1142$ & $342 / 537$ & $623 / 718$ \\
national charity & -0.024 & -0.059 & 0.116 \\
& $(0.029)$ & $(0.069)$ & $(0.063)$ \\
& $983 / 1142$ & $342 / 537$ & $623 / 718$ \\
Notes & 0.007 & 0.000 & 0.030 \\
& $(0.036)$ & $(0.086)$ & $(0.056)$ \\
& $983 / 1142$ & $342 / 537$ & $623 / 718$ \\
& -0.098 & -0.168 & 0.148 \\
& $(0.038)$ & $(0.079)$ & $(0.062)$ \\
& $983 / 1142$ & $342 / 537$ & $623 / 718$ \\
\hline
\end{tabular}

Notes: The entries report the results from propensity score matching routines. The row headings report the dependent variables. The samples and treatment are noted in the column headings. The entries report the unweighted impact of HBCU matriculation (graduation), relative to TWI matriculation (graduation). The propensity score is estimated with a probit and all of the covariates used in Table 2 are included as explanatory variables. The matching method uses a gaussian kernel with a bandwidth of 0.1 . The standard errors (reported in parentheses) are computed by bootstrapping, with propensity scores recomputed for each bootstrap sample. For each outcome, all observations with data on that outcome are used. Indexes are first principal components of sets of variables, normalized to have mean 0 and variance 1 . In constructing each index, we include every observation that has data on at least one variable in the set, by replacing any missing data with the mean of the corresponding variable. Numbers underneath standard error are number of HBCU and TWI students, respectively. Observations are dropped if the propensity score is not strictly between 0 and 1 . See the text and notes to Table 3 for more details. 
Table 7: Relative Changes Between the 1970s and 1990s

\begin{tabular}{|c|c|c|c|c|c|c|c|c|}
\hline & (1) & $(2)$ & $(3)$ & $(4)$ & (5) & (6) & $(7)$ & $(8)$ \\
\hline \multicolumn{9}{|l|}{ A. Sample Restricted to Blacks } \\
\hline Dependent Variable: & $\begin{array}{l}\text { In (wage) } \\
\text { (NLS/BB) }\end{array}$ & $\begin{array}{c}\text { Choose } \\
\text { College Again }\end{array}$ & $\begin{array}{l}\text { Pct. Black } \\
\text { in Zip Code }\end{array}$ & $\begin{array}{l}\text { Leadership } \\
\text { Index }\end{array}$ & $\begin{array}{l}\text { Social } \\
\text { Interactions Index }\end{array}$ & Political & Social Service & Charity \\
\hline $1(\mathrm{HBCU}) * 1(1990 \mathrm{~s})$ & $\begin{array}{l}-0.197 \\
(0.094)\end{array}$ & $\begin{array}{l}-0.133 \\
(0.055)\end{array}$ & $\begin{array}{c}0.135 \\
(0.041)\end{array}$ & $\begin{array}{l}-0.329 \\
(0.130)\end{array}$ & $\begin{array}{l}-0.429 \\
(0.129)\end{array}$ & $\begin{array}{c}0.138 \\
(0.055)\end{array}$ & $\begin{array}{c}0.133 \\
(0.053)\end{array}$ & $\begin{array}{c}0.259 \\
(0.056)\end{array}$ \\
\hline Observations & 734 & 3255 & 2461 & 3252 & 3250 & 3269 & 3269 & 3269 \\
\hline R-squared & 0.17 & 0.04 & 0.16 & 0.07 & 0.03 & 0.08 & 0.09 & 0.05 \\
\hline \multicolumn{9}{|c|}{$\begin{array}{l}\text { B. Sample Restricted to Blacks and Whites that Attended TWIs } \\
\text { Dependent Variable is In (wage) from the NLS and BB }\end{array}$} \\
\hline 1 (Black) * 1(1990s) & $\begin{array}{c}0.055 \\
(0.071)\end{array}$ & $\begin{array}{l}0.043 \\
(0.097)\end{array}$ & $\begin{array}{c}0.134 \\
(0.065)\end{array}$ & - & - & - & - & - \\
\hline Observations & 9607 & 9607 & 9607 & - & - & - & - & - \\
\hline R-Squared & 0.11 & 0.13 & 0.11 & - & - & - & - & - \\
\hline Controls No Interactions & Yes & No & No & - & - & - & - & - \\
\hline Controls Interacted with Decade Indicators & No & Yes & No & - & - & - & - & - \\
\hline Controls Interacted with Race Indicators & No & No & Yes & - & - & - & - & - \\
\hline
\end{tabular}

Controls Interacted with Race Indicators

No

Notes: The table reports on the results from fitting equation (3) in Panel A and equation (4) in Panel B. In Panel A, the samples are composed of stacked data from the NLS and B\&B in column (1) and the 1976 and 1989 C\&B in columns (2)-(8) and the sample is limited to Blacks The dependent variable is denoted in the first row of the panel. This Panel's entries report on the parameter estimate associated with the interaction of indicators for $\mathrm{HBCU}$ attendance and for an observation from the 1990s cohort and its heteroskedastic standard error. In Panel B, the sample is comprised of Blacks and Whites that graduated (colulmn 1) from TWIs. Here, the dependent variable is always In (hourly wage). This Panel's entries report on the

parameter estimate associated with the interaction of indicators for Black and for an observation from the 1990s cohort and its heteroskedastic standar error. The covariates are noted in the row headings at the bottom of the panel. In both panels, the sample weights associated with the NLS and B\&B are used with the normalization that the weights for each cohort sum to 1 . (In the C\&B, all obsevations are weighted equally.) Thus, the two cohorts in each regression are equally weighted but some observations are counted more heavily than others within a cohort according to the sample weights. See the text for further details. 
Appendix Table 1: Basic Summary Statistics on the Historically Black Colleges and Universitie

\begin{tabular}{|c|c|c|c|c|c|}
\hline Numbe & College or University & Location & $\begin{array}{c}\text { Undergraduate } \\
\text { Enrollment }\end{array}$ & $\begin{array}{c}\text { Total } \\
\text { Enrollment }\end{array}$ & Type \\
\hline 1 & Alabama A\&M University & Normal, AL & 5,047 & 6,182 & Public \\
\hline 2 & Alabama State University & Montgomery, AL & 4,485 & 5,469 & Public \\
\hline 3 & Albany State University & Albany, GA & 3,228 & 3,649 & Public \\
\hline 4 & Alcorn State University & Alcorn State, MS & 2,962 & 3,544 & Public \\
\hline 5 & Allen University & Columbia, SC & 624 & 624 & Private \\
\hline 6 & Arkansas Baptist College & Little Rock, AR & 287 & 287 & Private \\
\hline 7 & Benedict College & Columbia, SC & 2,552 & 2,552 & Private \\
\hline 8 & Bennett College & Greensboro, NC & 572 & 572 & Private \\
\hline 9 & Bethune-Cookman College & Daytona Beach, FL & 3,090 & 3,090 & Private \\
\hline 10 & Bluefield State College & Bluefield, WV & 1,708 & 1,708 & Public \\
\hline 11 & Bowie State University & Bowie, MD & 4,020 & 5,319 & Public \\
\hline 12 & Central State University & Wilberforce, $\mathrm{OH}$ & 1,617 & 1,623 & Public \\
\hline 13 & Cheyney University of Pennsylvania & Cheyney, PA & 1,401 & 1,560 & Public \\
\hline 14 & Claflin University & Orangeburg, SC & 1,678 & 1,728 & Private \\
\hline 15 & Clark Atlanta University & Atlanta, GA & 3,667 & 4,469 & Private \\
\hline 16 & Coppin State College & Baltimore, MD & 3,451 & 4,306 & Public \\
\hline 17 & Delaware State University & Dover, DE & 3,440 & 3,722 & Public \\
\hline 18 & Dillard University & New Orleans, LA & 1,993 & 1,993 & Private \\
\hline 19 & Edward Waters College & Jacksonville, FL & 839 & 839 & Private \\
\hline 20 & Elizabeth City State University & Elizabeth City, NC & 2,604 & 2,664 & Public \\
\hline 21 & Fayetteville State University & Fayetteville, NC & 5,029 & 6,072 & Public \\
\hline 22 & Fisk University & Nashville, TN & 864 & 920 & Private \\
\hline 23 & Florida A\&M University & Tallahassee, FL & 10,552 & 12,154 & Public \\
\hline 24 & Florida Memorial University & Miami Gardens, FL & 1,945 & 2,004 & Private \\
\hline 25 & Fort Valley State University & Fort Valley, GA & 1,997 & 2,174 & Public \\
\hline 26 & Grambling State University & Grambling, LA & 4,573 & 5,164 & Public \\
\hline 27 & Hampton University & Hampton, VA & 5,325 & 6,309 & Private \\
\hline 28 & Harris-Stowe State University & St. Louis, MO & 1,662 & 1,662 & Public \\
\hline 29 & Howard University & Washington, DC & 7,164 & 10,930 & Private \\
\hline 30 & Huston-Tillotson College & Auston, TX & 675 & 706 & Private \\
\hline 31 & Interdenominational Theological Center & Atlanta, GA & - & 447 & Private \\
\hline 32 & Jackson State University & Jackson, MS & 6,660 & 8,416 & Public \\
\hline 33 & Jarvis Christian College & Hawkins, TX & 572 & 572 & Private \\
\hline 34 & Johnson C. Smith Universit) & Charlotte, NC & 1,404 & 1,404 & Private \\
\hline 35 & Kentucky State University & Frankfort, KY & 2,228 & 2,386 & Public \\
\hline 36 & Knoxville College & Knoxville, TN & 300 & 300 & Private \\
\hline 37 & Lane College & Jackson, TN & 1,213 & 1,213 & Private \\
\hline 38 & Langston University & Langston, OK & 3,001 & 3,151 & Public \\
\hline 39 & Lemoyne-Owen College & Memphis, TN & 809 & 809 & Private \\
\hline 40 & Lincoln University & Jefferson City, MO & 2,953 & 3,180 & Public \\
\hline 41 & Lincoln University & Lincoln University, PA & 1,714 & 2,278 & Public \\
\hline 42 & Livingstone College & Salisbury, NC & 895 & 895 & Private \\
\hline 43 & Meharry Medical College & Nashville, TN & - & 707 & Private \\
\hline 44 & Miles College & Fairfield, $\mathrm{AL}$ & 1,758 & 1,758 & Private \\
\hline 45 & Mississippi Valley State University & Itta Bena, MS & 2,748 & 3,165 & Public \\
\hline 46 & Morehouse College & Atlanta, GA & 3,029 & 3,029 & Private \\
\hline 47 & Morehouse School of Medicine & Atlanta, GA & - & 272 & Private \\
\hline 48 & Morgan State University & Baltimore, MD & 5,747 & 6,438 & Public \\
\hline 49 & Morris Brown College & Georgia & 66 & 66 & Private \\
\hline 50 & Morris College & Sunter, SC & 863 & 863 & Private \\
\hline 51 & Norfolk State University & Norfolk, VA & 5,337 & 6,096 & Public \\
\hline 52 & North Carolina A\&T State University & Greensboro, NC & 9,735 & 11,103 & Public \\
\hline 53 & North Carolina Central University & Durham, NC & 6,353 & 8,219 & Public \\
\hline 54 & Oakwood College & Huntsville, AL & 1,751 & 1,751 & Private \\
\hline 55 & Paine College & Augusta, GA & 828 & 828 & Private \\
\hline 56 & Paul Quinn College & Dallas, TX & 790 & 790 & Private \\
\hline 57 & Philander Smith College & Little Rock, AR & 785 & 785 & Private \\
\hline 58 & Prairie View A\&M University & Prairie View, TX & 5,702 & 7,912 & Public \\
\hline 59 & Rust College & Holly Springs, MS & 970 & 970 & Private \\
\hline 60 & Saint Paul's College & Lawrenceville, VA & 717 & 717 & Private \\
\hline 61 & Savannah State University & Savannah, GA & 2,975 & 3,091 & Public \\
\hline
\end{tabular}




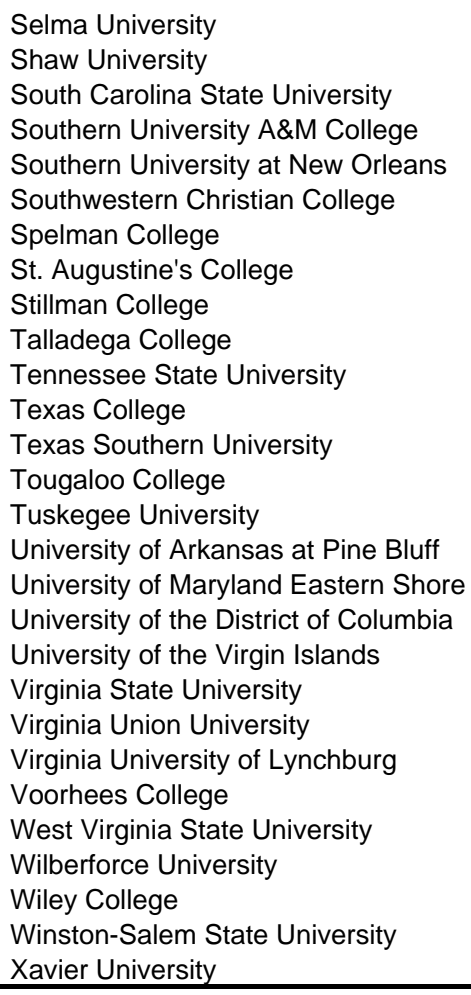

Selma, AL

$287 \quad 287 \quad$ Private

Raleigh, NC

2,565

2,762 Private

Orangeburg, SC

4,446 Public

Baton Rouge, LA

3,888

New Orleans, LA

10,364 Public

Terrell, TX

3,647 Public

Atlanta, GA

Raleigh, NC

Tuscaloosa, AL

Talladega

Nashville, TN

Tyler, TX

8,969

2,824

251

2,318

1,163

Private

804

2,318

1,163

Private

Private

$368 \quad 368 \quad$ Private

$7,036 \quad 8,880 \quad$ Public

Houston, TX

Tougaloo, MS

794

807

Private

Tuskegee, AL

9,760

11,903

Public

Pine Bluff, AR

Princess Anne, MD

2,880

Private

Washington, DC

Charlotte Amalie, VI

Public

3,132

3,448

3,870

Public

Petersburg, VA

Richmond, VA

Lynchburg, VA

5,169

5,363

Public

2,185 2,392 Public

4,332 5,055 Public

$1,344 \quad 1,700$ Private

Denmark, SC

Private

Institute, WV

122

709

Private

Wilberforce, $\mathrm{OH}$

3,491

Public

Marshall, TX

1,157

1,170

Private

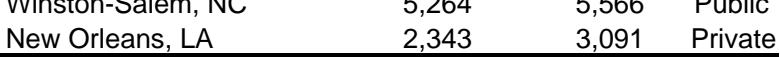

Notes: The list of schools is taken from the US Department of Education's web site:

http://www.ed.gov/about/inits/list/whhbcu/edlite-list.html. The location data and enrollment information (current as of Fall 2005) is from the National Center for Education Statistics's site: http://nces.ed.gov. 
Appendix Table 2: Is there Heterogeneity in the Impact of HBCU Attendance in the NLS and B\&B?

\begin{tabular}{|c|c|c|c|c|c|c|}
\hline \multirow{2}{*}{$\begin{array}{l}\text { Dataset } \\
\text { HBCU Definition }\end{array}$} & \multicolumn{2}{|c|}{$\frac{\mathrm{NLS}(1972)}{\text { first college }}$} & \multicolumn{2}{|c|}{$\begin{array}{c}\text { bachelor's degree college } \\
\text { bLS (1972) }\end{array}$} & \multicolumn{2}{|c|}{$\begin{array}{c}\text { bB (1997) } \\
\text { bachelor's degree college }\end{array}$} \\
\hline & (1) & $(2)$ & (3) & $(4)$ & (5) & $(6)$ \\
\hline A. Propensity score range & 0 to 0.5 & 0.5 to 1.0 & 0 to 0.5 & 0.5 to 1.0 & 0 to 0.5 & 0.5 to 1.0 \\
\hline Kernel matching & $\begin{array}{c}0.141 \\
(0.077)\end{array}$ & $\begin{array}{c}0.093 \\
(0.072)\end{array}$ & $\begin{array}{c}0.102 \\
(0.114)\end{array}$ & $\begin{array}{c}0.043 \\
(0.098)\end{array}$ & $\begin{array}{l}-0.118 \\
(0.050)\end{array}$ & $\begin{array}{l}-0.157 \\
(0.100)\end{array}$ \\
\hline Number $\mathrm{HBCU}$ & 99 & 104 & 44 & 88 & 88 & 36 \\
\hline Number TWI & 236 & 49 & 116 & 44 & 251 & 18 \\
\hline B. North vs. south & North & South & North & South & North & South \\
\hline$\overline{\text { Kernel matching }}$ & $\begin{array}{l}-\overline{0.063} \\
(0.150)\end{array}$ & $\begin{array}{c}\overline{0.144} \\
(0.065)\end{array}$ & $\begin{array}{c}\overline{0.091} \\
(0.279)\end{array}$ & $\begin{array}{l}0.076 \\
(0.107)\end{array}$ & $\begin{array}{l}-\overline{-0.125} \\
(0.141)\end{array}$ & $\begin{array}{l}-\overline{-0.174} \\
(0.059)\end{array}$ \\
\hline Number HBCU & 28 & 171 & 18 & 111 & 32 & 85 \\
\hline Number TWI & 96 & 133 & 46 & 76 & 95 & 131 \\
\hline C. At least 1 parent has bachelor's & No & $\underline{\text { Yes }}$ & No & Yes & No & $\underline{\text { Yes }}$ \\
\hline Kernel matching & $\begin{array}{c}0.149 \\
(0.065)\end{array}$ & $\begin{array}{l}-0.011 \\
(0.283)\end{array}$ & $\begin{array}{c}0.066 \\
(0.098)\end{array}$ & $\begin{array}{l}- \\
-\end{array}$ & $\begin{array}{l}-0.163 \\
(0.058)\end{array}$ & $\begin{array}{l}-0.117 \\
(0.095)\end{array}$ \\
\hline Number $\mathrm{HBCU}$ & 177 & 22 & 118 & 11 & 67 & 55 \\
\hline Number TWI & 240 & 23 & 124 & 0 & 185 & 48 \\
\hline D. SAT score & Below median & Above median & Below median & Above median & Below median & Above median \\
\hline Kernel matching & $\begin{array}{c}-0.011 \\
(0.117)\end{array}$ & $\begin{array}{c}0.087 \\
(0.166)\end{array}$ & $\begin{array}{l}-0.348 \\
(0.296)\end{array}$ & $\begin{array}{c}0.219 \\
(0.242)\end{array}$ & $\begin{array}{l}-0.161 \\
(0.087)\end{array}$ & $\begin{array}{c}0.045 \\
(0.114)\end{array}$ \\
\hline Number HBCU & 58 & 28 & 35 & 18 & 42 & 24 \\
\hline Number TWI & 37 & 52 & 31 & 23 & 57 & 64 \\
\hline E. Male vs. female & Male & Female & Male & Female & Male & Female \\
\hline Kernel matching & $\begin{array}{l}-0.078 \\
(0.100)\end{array}$ & $\begin{array}{c}0.185 \\
(0.071)\end{array}$ & $\begin{array}{l}-0.035 \\
(0.136)\end{array}$ & $\begin{array}{c}0.091 \\
(0.124)\end{array}$ & $\begin{array}{l}-0.291 \\
(0.109)\end{array}$ & $\begin{array}{l}-0.117 \\
(0.061)\end{array}$ \\
\hline Number HBCU & 67 & 136 & 47 & 85 & 34 & 90 \\
\hline Number TWI & 69 & 156 & 39 & 76 & 70 & 183 \\
\hline
\end{tabular}

Notes: The entries report the results from propensity score matching routines. In all cases, the dependent variable is In (hourly wage). The sample and treatment are noted in the column headings. The entries report the impact of HBCU matriculation (graduation), relative to TWI matriculation

(graduation). Panels A-E test for heterogeneity in the impact of $\mathrm{HBCU}$ attendance by an estimated propensity score above or below 0.5 (Panel A), attending high school in the North versus the South (Panel B), whether at least one parent has a bachelor's degree (Panel C), a SAT score above or below the median in the sample (Panel D), and by gender (Panel E). The propensity score is estimated with a probit and all of the covariates used in Table 2 are included as explanatory variables. The matching method uses a gaussian kernel with a bandwidth of 0.1 . The standard errors (reported in parentheses) are computed by bootstrapping, with propensity scores recomputed for each bootstrap sample. The estimates are

unweighted. Observations are dropped if wages are missing or zero or the propensity score in the full sample is not strictly between 0 and 1 . See the text and notes to Tables 3 and 4 for more details. 
Figure 1: Kernel Density Plots of the Distribution of Estimated Propensity Scores for HBCU Graduation, by TWI and HBCU Graduates from National Longitudinal Survey (Based on Weighted Probit)

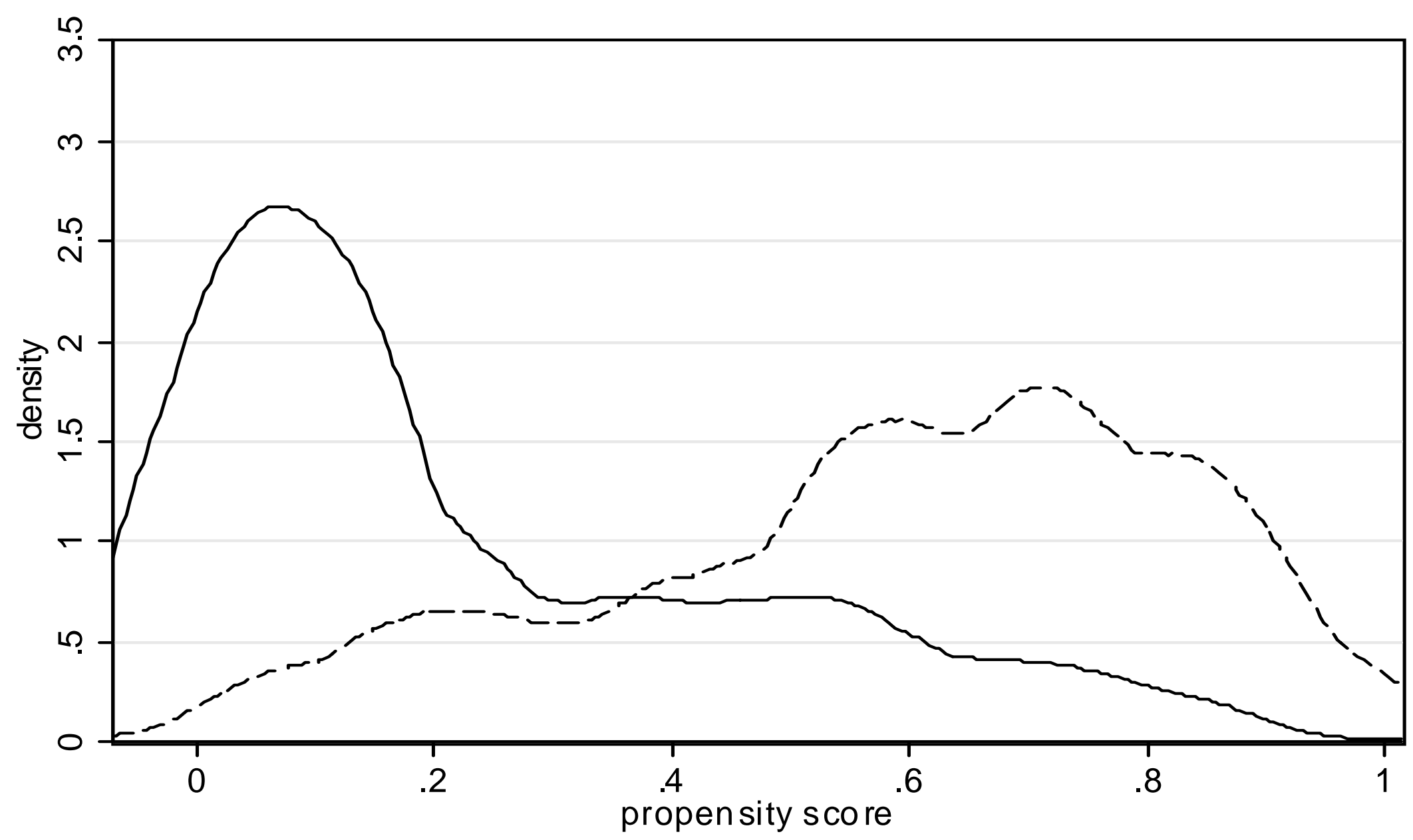

attended TW I - - - -- attend ed HBCU 
Figure 2: Kernel Density Plots of the Distribution of Estimated Propensity Scores for HBCU Graduation, by TWI and HBCU Graduates from Baccalaureate and Beyond (Based on Weighted Probit)

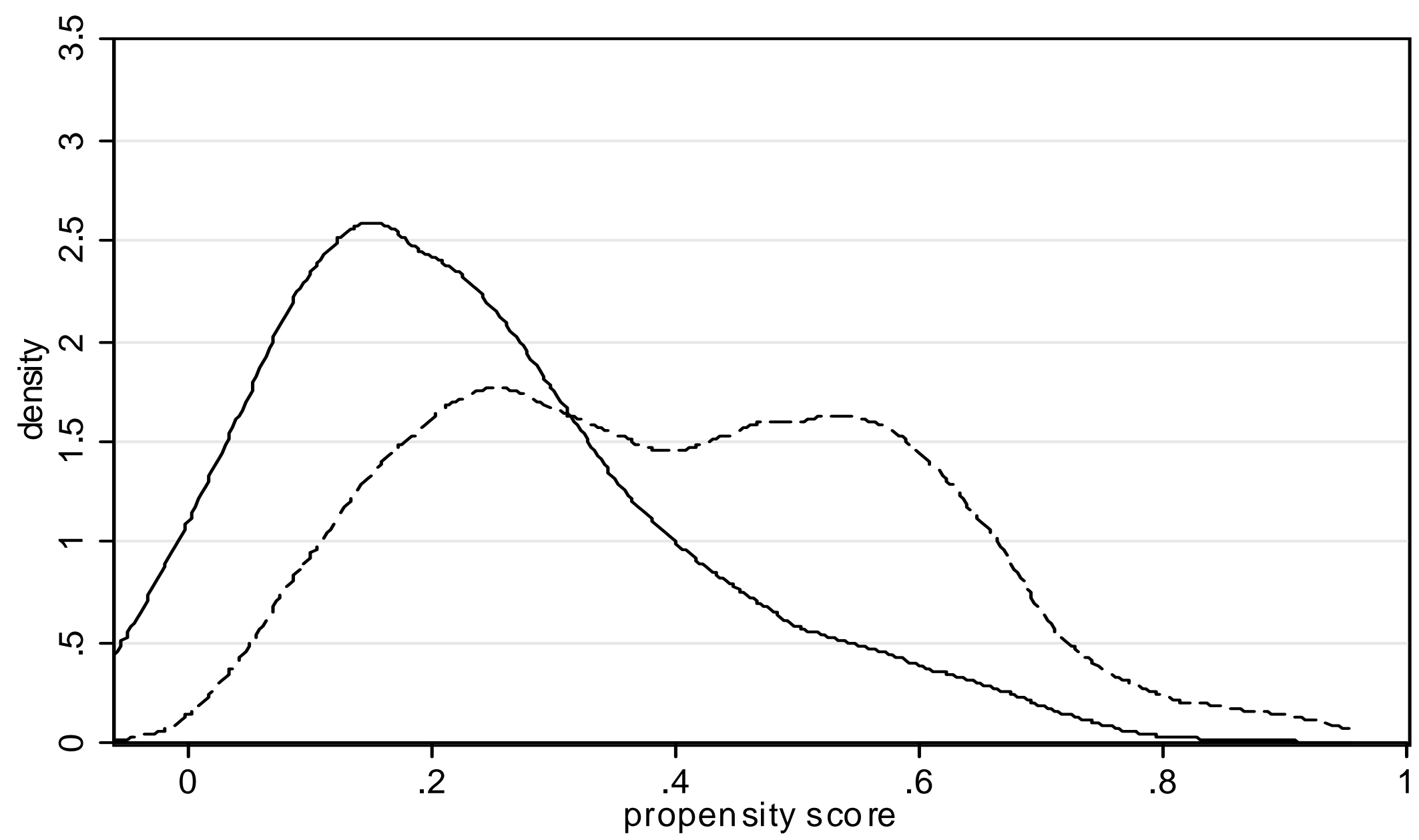

attended TW I - - - - attend ed HBCU 
Figure 3: Kernel Density Plots of the Distribution of Estimated Propensity Scores for HBCU Matriculation,

by TWI and HBCU Matriculates from 1976 College and Beyond (Based on Probit, excluding Howard and Spelman)

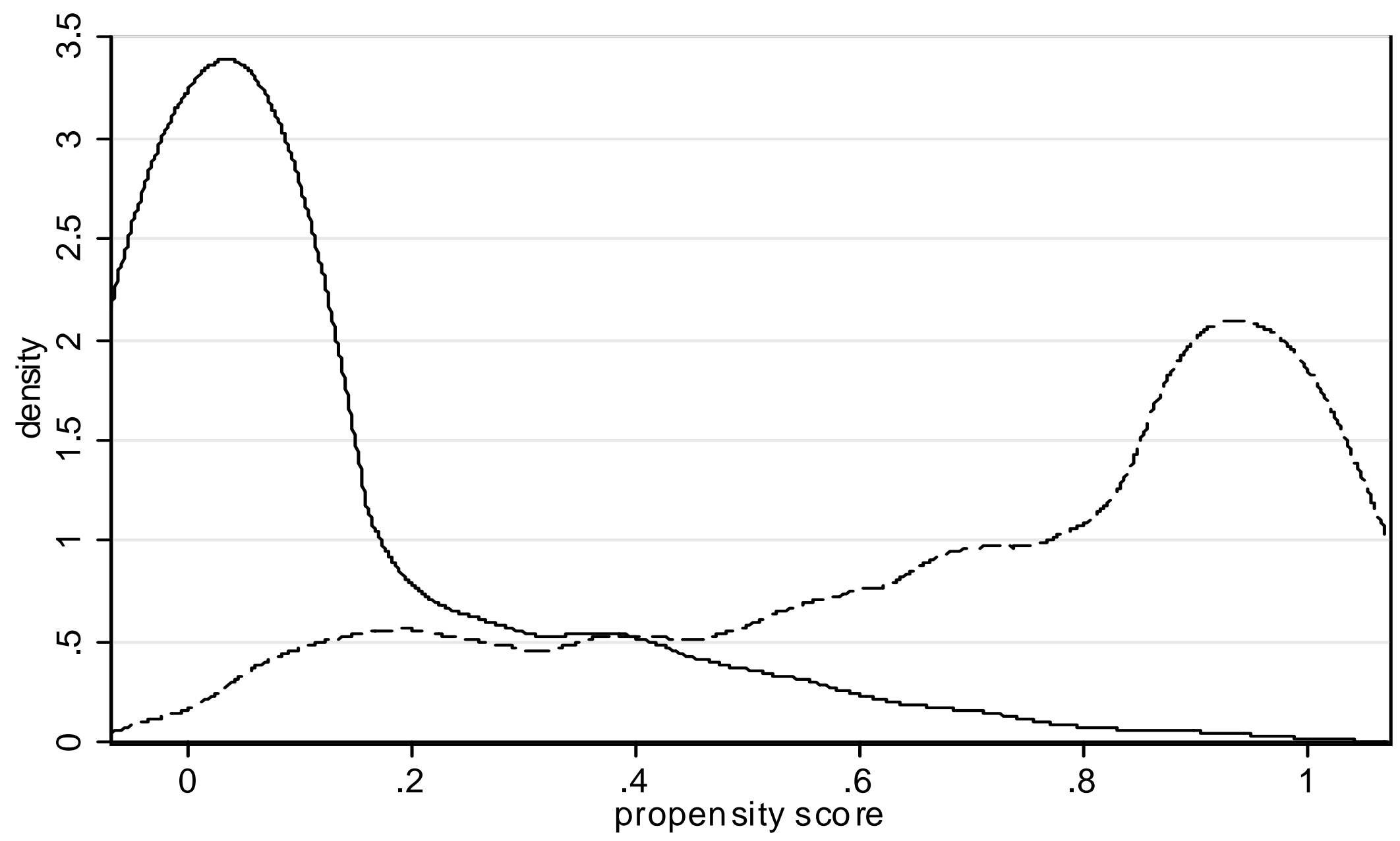

attended TW I - - - - attended HBCU 
Figure 4: Kernel Density Plots of the Distribution of Estimated Propensity Scores for HBCU Matriculation, by TWI and HBCU Matriculates from 1989 College and Beyond (Based on Probit)

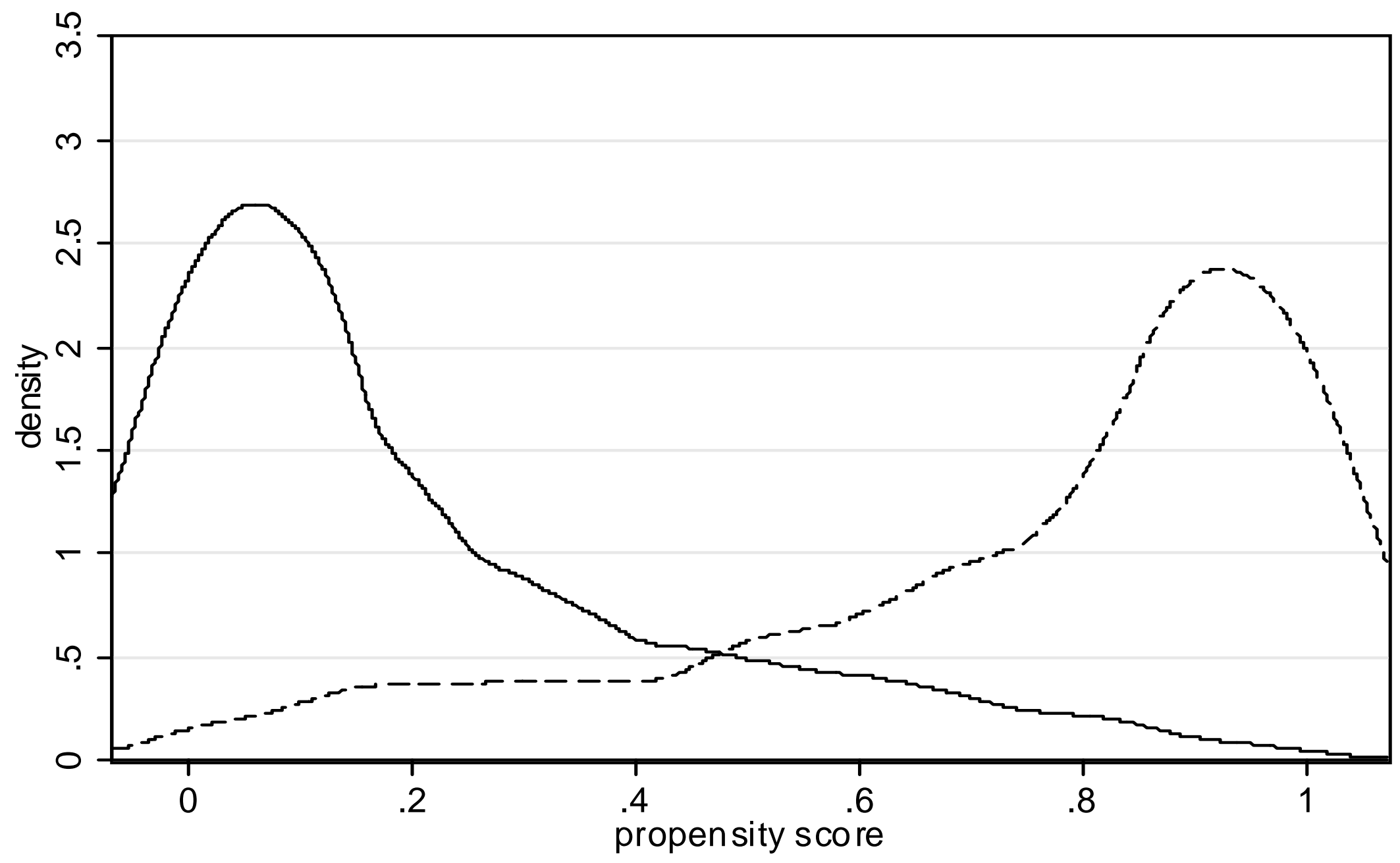

attended TWI - - - - attend ed HBCU 